\title{
Standard methods for Nosema research
}

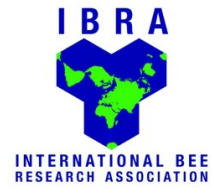

\section{Ingemar Fries ${ }^{1 *}$, Marie-Pierre Chauzat ${ }^{2}$, Yan-Ping Chen ${ }^{3}$, Vincent Doublet ${ }^{4}$, Elke Genersch ${ }^{6}$, Sebastian Gisder ${ }^{6}$, Mariano Higes ${ }^{7}$, Dino P McMahon ${ }^{5}$, Raquel Martín-Hernández ${ }^{7}$, Myrsini Natsopoulou ${ }^{4}$, Robert J Paxton ${ }^{4,5}$, Gina Tanner ${ }^{8}$, Thomas C Webster ${ }^{9}$ and Geoffrey R Williams ${ }^{8}$}

\author{
${ }^{1}$ Department of Ecology, Swedish University of Agricultural Sciences, 75007 Uppsala, Sweden. \\ ${ }^{2}$ Anses, Unit of honey bee pathology, 105 route des Chappes, BP 111, F06 902 Sophia Antipolis cedex, France. \\ ${ }^{3}$ Bee Research Laboratory, USDA-ARS, Beltsville, MD, USA. \\ ${ }^{4}$ Institute for Biology, University of Halle-Wittenberg, 06099 Halle (Saale), Germany. \\ ${ }^{5}$ School of Biological Sciences, Queen's University Belfast, Belfast BT9 7BL, UK. \\ ${ }^{6}$ Department for Molecular Microbiology and Bee Diseases, Institute for Bee Research Hohen Neuendorf, 16540 Hohen \\ Neuendorf, Germany. \\ ${ }^{7}$ Centro Apícola de Castilla-La Mancha, Laboratorio de Patología, San Martín s/n, 19180 Marchamalo, Spain. \\ ${ }^{8}$ Swiss Bee Research Centre, Agroscope Liebefeld-Posieux Research Station ALP-HARAS, Bern, Switzerland. \\ ${ }^{9}$ Land Grant Program, Kentucky State University, Frankfort, KY 40601, USA.
}

Received 10 April 2012, accepted subject to revision 14 June 2012, accepted for publication 29 October 2012.

*Corresponding author: Email: Ingemar.Fries@slu.se

\section{Summary}

Methods are described for working with Nosema apis and Nosema ceranae in the field and in the laboratory. For fieldwork, different sampling methods are described to determine colony level infections at a given point in time, but also for following the temporal infection dynamics. Suggestions are made for how to standardise field trials for evaluating treatments and disease impact. The laboratory methods described include different means for determining colony level and individual bee infection levels and methods for species determination, including light microscopy, electron microscopy, and molecular methods (PCR). Suggestions are made for how to standardise cage trials, and different inoculation methods for infecting bees are described, including control methods for spore viability. A cell culture system for in vitro rearing of Nosema spp. is described. Finally, how to conduct different types of experiments are described, including infectious dose, dose effects, course of infection and longevity tests.

\section{Métodos estándar para la investigación sobre Nosema}

\section{Resumen}

Se describen procedimientos para trabajar con Nosema apis y Nosema ceranae en el campo y en el laboratorio. Para el trabajo de campo, se describen diferentes métodos de muestreo para determinar infecciones al nivel de colonia en un momento determinado, y también para el seguimiento de la dinámica temporal de infección. Se hacen sugerencias para la forma de estandarizar los ensayos de campo para evaluar los tratamientos y el impacto de la enfermedad. Los métodos de laboratorio descritos incluyen diferentes formas de determinar los niveles de infección al nivel de colonia y de abeja individual, y los métodos para la determinación de las especies, incluyendo microscopía óptica, microscopía electrónica y métodos moleculares (PCR). Se hacen sugerencias para estandarizar los ensayos con cajas, y se describen diferentes métodos de inoculación para infectar abejas, incluyendo métodos de control para la viabilidad de las esporas. Se describe un sistema de cultivo celular para la cría in vitro de Nosema spp. Finalmente, se describe cómo llevar a cabo diferentes tipos de experimentos, incluyendo la dosis infecciosa, efectos de la dosis, curso de la infección y las pruebas de longevidad. 


\section{孢子虫研究的标准方法}

本文描述了实验室及野外实验中关于孢子虫Nosema apis 和 Nosema ceranae 的研究方法。对于野外实验, 本文列举了多种取样方法, 用于研究 特定时间段内, 蜂群群体感染水平, 以及随后开展长期感染规律的研究。同时也对如何标准化评估蜂场治疗效果、感病程度及选用哪些指标用于 标准化评估提出了建议。实验室方法包括, 确定蜂群感染水平及个体蜜蜂感染水平的方法以及测定孢子虫种类的方法, 如光学显微镜法, 电子显 微镜法以及分子方法（PCR）。对于如何标准化蜂笼实验的各项指标提出了建议，并描述了感染蜜蜂的不同接种方法，包括狍子生存能力的对比 法。描述了孢子虫的一种体外细胞培养体系。最后描述了如何进行不同类型的实验, 包括感染剂量、剂量效能、感染过程以及寿命试验。

Keywords: Nosema apis, Nosema ceranae, field methods, laboratory methods, sampling methods, infection dynamics, infection level, microscopy, species identification, standardised cage trials, inoculation methods, spore viability, cell culture, infectious dose, dose effects, course of infection, longevity tests, honey bee, BEEBOOK, COLOSS

\section{Table of Contents}

2. Method type

2.1. Field methods

2.1.1. Colony level infection

2.1.1.1 Sampling

2.1.1.2. Sample size

2.1.1.3 Clinical signs and symptoms of infection

2.1.2 Colony level infection dynamics

2.1.2.1. Sampling period and sampling frequency

2.1.3. Standardising field trials

2.1.3.1. Selection of colonies

2.1.3.2 Behaviour of infected bees

2.1.3.3. Parameters to record

2.2 Laboratory methods

2.2.1. Colony and individual level infection

2.2.1.1. Spore counts

2.2.1.2. Individual bees or pooled samples

2.2.1.3. Parts to examine

2.2.2. Nosema species identification

2.2.2.1. Light microscopy (LM)

2.2.2.1.1. Giemsa staining

2.2.2.1.2. Toluidine staining

2.2.2.2. Transmission electron microscopy (TEM)

2.2.2.3. Molecular detection of Nosema spp. (N. apis, N. ceranae 8 and $N$. bombi)

2.2.2.3.1. Nosema DNA extraction

2.2.2.3.2. Multiplex PCR for detection of Nosema and differentiation between $N$. apis, N. bombi and N. ceranae

2.2.2.3.2.1. PCR reaction mix

2.2.2.3.2.2. Visualization

2.2.2.3.2.3. Controls

2.2.2.3.3. Realtime PCR for quantification of $N$. apis and $N$. ceranae

2.2.2.3.3.1. $\quad$ PCR reaction mix

2.2.2.3.3.2. Quantification

2.2.2.3.3.3. Controls

2.2.3.

Standardising cage trails
Page

No.

$3 \quad$ 2.2.3.1. Source of bees

$3 \quad$ 2.2.3.1.1. Source colonies

$3 \quad$ 2.2.3.1.2. Age of bees 12

$3 \quad$ 2.2.3.2. Type of cages 12

$4 \quad$ 2.2.3.3. Type of food 13

$4 \quad$ 2.2.3.4. Incubation conditions 13

$4 \quad$ 2.2.4. Inoculation methods

$4 \quad$ 2.2.4.1. Spore source

$4 \quad$ 2.2.4.2. Spore suspension

5 2.2.4.2.1. Purification 14

5 2.2.4.2.1.1. Centrifugation 14

$5 \quad$ 2.2.4.2.1.2. Triangulation 14

$5 \quad$ 2.2.4.2.1.3. Density Gradient 14

$5 \quad$ 2.2.4.2.2. Spore suspension concentration 14

$5 \quad$ 2.2.4.2.3. Storage of stock suspension 15

5 2.2.4.3. Handling of bees 15

5 2.2.4.4. Individual feeding 15

$6 \quad$ 2.2.4.5. Group feeding 16

$6 \quad 2.2 .5 . \quad$ Viability control of Nosema spores 16

$6 \quad$ 2.2.5.1. Colouration test for spore viability 16

$7 \quad$ 2.2.5.2. In vivo test for spore viability

$7 \quad$ 2.2.5.3. In vitro test for spore viability

8 2.2.6. In vitro rearing of Nosema spp.:cell culture systems 17

2.2.6.1. Infection of primary honey bee ventricular cells 17

2.2.6.2. Infection of heterologous lepidopteran cell lines 18

2.2.7. Experiment type 19

2.2.7.1. Determination of infectious does 19

2.2.7.1.1. Study of dose effects 20

2.2.7.1.2. Effects of different infection doses 20

2.2.7.2. Course of infection in individual bees 20

2.2.7.3. Longevity of infected bees 20

3. Future perspectives 20

4. Acknowledgements 21

5. References 21

21
21

age

(1)

3

4

.

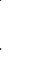
4 . (1)

.
16

7

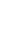

8

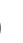
20 20 


\section{Introduction}

Since the description of Nosema apis in the early part of the last century (Zander, 1909), nosema disease, or nosemosis of honey bees has been regarded as a serious obstacle for profitable beekeeping in temperate climates (Fries, 1993). With the detection of the new parasite Nosema ceranae, originally described from the Asian honey bee Apis cerana (Fries et al., 1996), in European honey bees (Higes et al., 2006) the need for research in this field has become urgent. In particular, since early reports on the effects of this new parasite suggested a more severe impact on colony health compared to infections by $N$. apis (Higes et al., 2008a). Following the COLOSS workshop "Nosema disease: lack of knowledge and work standardization" in Guadalajara (19-22 October, 2009) data were collected on the heterogeneity of methods used in Nosema research in different laboratories in Europe and in the USA. This survey showed the widely heterogeneous experimental conditions applied in the nine different participating laboratories. Even if common sense implies that some conditions should be applied in all cases, their costs and the availability of these analyses have to be taken into account. For example, one could be tempted to assert that virus presence has to be checked in colonies providing honey bees for Nosema experiments, but some laboratories are not equipped with virus diagnostics, and this could restrict these teams from performing experiments on Nosema without controlling for confounding viral infections. The level and extent of diagnosis should also be specified: which viruses should be studied, is viral detection sufficient, or should virus quantification be included?

Here we attempt to standardize study of the microsporidians Nosema apis and Nosema ceranae. Nosema apis, the historical microsporidian parasite of European honey bees, can decrease worker longevity and cause considerable winter colony losses (Fries, 1993), whilst $N$. ceranae, probably introduced into European honey bees from its Asian congener (Apis cerana) within the last few decades (Higes et al., 2006; Martín-Hernández et al., 2007; Klee et al., 2007; Paxton et al., 2007; Chen et al., 2008; Williams et al., 2008; Invernizzi et al., 2009; Currie et al., 2010; Botías et al., 2011), is associated with colony depopulation and collapse in warmer areas of Europe (Higes et al., 2008a), but not in northern parts of Europe (Gisder et al., 2010a), in North America (Guzman-Nova, 2010; Williams et al., 2010) or in South America (Invernizzi et al., 2009). Yet because detection of $N$. ceranae in European honey bees coincided with recent large-scale honey bee colony losses throughout the world, data on the pathology and management of this parasite are of significant interest.

When working in the field with full-sized colonies, several considerations need to be made, such as where to sample, how often to sample and also the size of samples. We find, for example, that sample sizes are often too small to satisfy a statistically reasonable level of diagnostic precision (Fries et al., 1984). Please refer to the section on statistics in the BEEBOOK paper on miscellaneous methods (Human et al., 2013) to determine sample size.
Similarly, laboratory tests using bees in cages are often employed to investigate Nosema intra-host development (e.g. Higes et al., 2007; 2010; Martín-Hernández et al., 2009; Forsgren and Fries, 2010), effects of parasitism on host mortality (e.g. Paxton et al., 2007), immunity (e.g. Antúnez et al., 2009), and physiology (e.g. Dussaubat et al., 2010; Mayack and Naug, 2009; Martín-Hernández et al., 2011), as well as for testing the efficacy of potential control treatments (e.g. Maistrello et al., 2008; Higes et al., 2011). When designing cage experiments, researchers typically must control for a number of variables, ranging from selection of study subjects (e.g. parasite and host strains) to experimental environment (e.g. growth chamber conditions, food quality and quantity). Although decisions typically do not jeopardize the scientific rigor of a study, they may profoundly affect results, and may make comparisons with similar, independent studies difficult. An important consideration is that most current data on Nosema were collected from experiments with $N$. apis. The same research is now needed for $N$. ceranae in order to assess the similarities and differences between the two species.

Here we discuss some important factors that researchers must consider when studying the Nosema-honey bee system using field as well as laboratory cage experiments. This will allow researchers to make informed choices when developing experimental protocols and will increase confidence when comparing results among studies.

\section{Method type}

\subsection{Field methods}

\subsubsection{Colony level infection}

The degree of Nosema spp. infection in a colony has most commonly been described through the average number of spores per bee in a pooled sample (Cantwell, 1970; OIE, 2008). However, some studies suggest that the best way to determine the degree of infection is to estimate the proportion of infected bees in the colony (L'Arrivee, 1963; Doull, 1965; Higes et al., 2008a; Botías et al., 2012a). Nevertheless, there is a good correlation between the proportion of infected bees and the average number of spores in a pooled sample of bees (Fries et al., 1984), but not in all cases (Higes et al., 2008a). Evaluating the proportion of infected bees is much more laborious than to count the number of spores in a pooled sample, so pooled sampling will probably remain an important tool for quantifying infections in colonies.

Because there is a wide variation in the numbers of spores found in individual bees in pooled samples, when the highest precision is needed, it may still be motivating to investigate the proportion of infected bees. The highest proportion of infected bees are found in foraging bees (Higes et al., 2008a, b; Botías et al., 2012a,b; Meana et al., 2010; Smart and Sheppard, 2011), as is the greatest infection (spores per bee) (El-Shemy and Pickard, 1989). Recent studies suggest the importance of determining the proportion of infected house bees to establish the viability and impact from infection on 
colonies (Botías et al., 2012a). Considerations regarding pooled sampling versus individual bee diagnosis are discussed in section 2.2.1.2.

\subsubsection{Sampling}

For the diagnosis and detection of Nosema spp.-infected colonies, the oldest honey bees should be the target population, since they are more frequently infected compared to younger bees (Meana et al., 2010; Smart and Sheppard, 2011). Forager bees can be sampled outside the entrance. This method is useful in all areas during flight and foraging conditions. Caution should be taken to avoid collection of young bees performing their orientation flights. The time of the day of these flights could change in different geographic areas. Bees that conduct their orientation flights are easily recognized by the hovering behaviour in large numbers outside the entrance. When this behaviour is seen, attempts to sample for foragers should be avoided.

During non-flight conditions, old bees may still be the target population for diagnosis. To avoid sampling of newly emerged, uninfected bees, the samples can either be taken from peripheral combs in the brood area, without hatching bees, or in a super above a queen excluder. The variation introduced by not sampling flight bees is unfortunate, because it reduces the possibility for meaningful comparisons between sites. Nevertheless, when samples are taken during late autumn or winter or during the active season outside of foraging conditions (e.g. study of infection development across the year), bees from within the hive must be sampled.

To determine the degree of infection within colonies, both pooled sampling or individual sampling of bees can be used (see section

2.2.1.2). Samples should preferably be stored in the deep freezer until further processing.

\subsubsection{Sample size}

Please refer to the statistics section in the BEEBOOK paper on miscellaneous methods (Human et al., 2013).

\subsubsection{Clinical signs and symptoms of infection}

The effects from $N$. apis infections on honey bee colonies have been extensively documented (Fries, 1993). This disease is characterized (in acute forms) by the trembling of honey bee workers or dead bees around the hive. Bees may also exhibit a dilated abdomen and brown faecal marks on the comb and the front of the hives are often found. Further, heavily infected colonies have a decrease in brood production and slow colony growth, particularly in spring (Bailey, 1955; OIE, 2008). Although $N$. apis is correlated with winter mortality of infected colonies, the disease also appears without causing losses of infected colonies (Bailey, 1955). Colony level symptoms produced by $N$. ceranae infections have been described to be different from $N$. apis symptoms (Higes et al., 2008; 2009). A gradual depopulation of adult honey bees. bees, higher autumn / winter colony mortality, and finally the queen surrounded by only young bees have been observed in southern Europe (Higes et al., 2006; 2008; 2009), whereas such severe symptoms or effects have not been described from more temperate climates (Gisder et al., 2010a) nor from South (Invernizzi et al., 2009) or North (Williams et al., 2011; Guzman-Novoa et al., 2010) America. Possibly, differences in honey bee subspecies, foraging conditions, agricultural practices, differences in hive management practices, or other abiotic or biotic factors may contribute to the variation in symptoms described for $N$. ceranae infections in different regions of the world. Further research efforts using standardized methodologies are most certainly warranted.

\subsubsection{Colony level infection dynamics}

The temporal dynamics of $N$. apis infections in temperate climates have been described by many authors (White, 1919; Borchert, 1928; Michailoff, 1928; Bailey, 1955; Furgala and Hyser, 1969; Furgala and Mussen, 1978), with a similar pattern in both northern and southern hemispheres (Doull and Cellier, 1961). In short, the typical infection exhibits low prevalence during the summer, a small peak in the autumn, and a slow rise of infection during the winter. In the spring, infections increase rapidly as brood rearing starts while flight possibilities are still limited. There are few data on the temporal dynamics on $N$. apis infections in tropical or sub-tropical climates, but the infection appears to be present but with low impact on colony fitness (Wilson and Nunamaker, 1983) and probably without the pronounced temporal dynamics observed in temperate climates (Fries et al., 2003). For $N$. ceranae, few long-term studies have been performed on the temporal dynamics of this infection in honey bee colonies. Studies from central Spain suggest much less variation in infection prevalence over the season for $N$. ceranae compared to what has been described for $N$. apis (Higes et al., 2008a). However, a clear seasonal effect on disease prevalence, with higher prevalence and infection levels in the early season has been documented in eastern USA (Traver and Fell, 2011; Traver et al., 2012) and in untreated colonies in maritime Canada (Williams et al., 2010; 2011). There is an urgent need for long-term studies of the temporal dynamics of $N$. ceranae infections under different climatic conditions.

\subsubsection{Sampling period and sampling frequency}

To gain information on how amounts and prevalence of infections change over time, it is necessary to monitor changes over more than one year. Samples should be taken with at least monthly intervals during the period when colonies can be opened without adverse effects on colony survival. For higher resolution of the temporal dynamics of infections, sampling must be bi-weekly or even weekly during periods of rapid change of infection prevalence, as described for $N$. apis during early spring. Refer to section 2.1.1.1. sampling 


\subsubsection{Standardising field trials}

\subsubsection{Selection of colonies}

A main problem with field trials using free flying honey bee colonies is the large natural variation in size, productivity or behaviour between colonies. In comparative field trials, it is therefore advisable to minimize such variations, and if considerable variation is expected, then increase the number of colonies involved. This can be achieved by using:

- Artificial swarms from healthy colonies

- Sister queens mated the same way or instrumentally inseminated (see BEEBOOK papers on queen rearing and selection (Büchler et al., 2013) and on instrumental insemination (Cobey et al., 2013))

- Adding a controlled degree of infection at the onset of the experiment

Adding a controlled degree of infection at the onset of the experiment can be achieved by adding a known number of bees with a documented degree of infection, either from naturally infected colonies, or from colonies where infections have been propagated for this purpose. Spores can also be sprayed onto combs and bees in sugar solution as is done with American foulbrood spores (see the BEEBOOK paper on American foulbrood (de Graaf et al., 2013)).

Naturally infected colonies can also be used for comparative studies after careful documentation of infection prevalence (see section 2.1.1.).

\subsubsection{Behaviour of infected bees}

There is a need to study if the impact on behaviour and physiology described from infections with $N$. apis also occurs during infections with $N$. ceranae. In particular, we need to find out:

- Do honey bees infected by $N$. ceranae start their foraging activities at a younger age compared to uninfected bees, as is the case for $N$. apis infections (Hassanein, 1953)?

- Do infections with $N$. ceranae cause a faster physiological aging of the bees, as is the case for $N$. apis infections (Wang and Muller, 1970)?

- Do bees infected by $N$. ceranae feed the queen less frequently compared to uninfected bees, as is the case for $N$. apis infections (Wang and Muller, 1970)?

- Are queen bees infected by $N$. ceranae superseded, as is the case for N. apis infections (Farrar, 1947)?

\subsubsection{Parameters to record}

The type of data to be collected during field experiments will vary depending on the objective of the study. Field studies often involve observing colonies and the development of disease in relation to different treatments or management practices. It is thus advisable to always report on certain standard parameters if possible, for interpretation of the data. Such parameters include:

- Intra-hive mortality (dead bee traps; see the BEEBOOK paper on miscellaneous methods (Human et al., 2013))

- Colony size and population dynamics (number of bees and amount of brood, see the BEEBOOK paper on estimating colony strength (Delaplane et al., 2013)

- Clinical signs of any diseases (see Volume II of the BEEBOOK)

- Varroa mite infestation (see the BEEBOOK paper on varroa (Dietemann et al., 2013))

- Honey production

- Climatic conditions during the experiment

- Subspecies of honey bees used (see the BEEBOOK paper on characterising subspecies and ecotypes (Meixner et al., 2013))

- Specific management practices

\subsection{Laboratory methods}

\subsubsection{Colony and individual level infection}

\subsubsection{Spore counts}

To determine the degree of infection of Nosema spp. in a sample it has been suggested that subjective judgement on an arbitrary infection scale can be used (Doull and Eckert, 1962; Gross and Ruttner, 1970). However, for research purposes, such estimations should not be employed if some degree of precision is required.

The easiest way to count Nosema spp. spores is to use a traditional haemocytometer as described in the miscellaneous methods paper of the BEEBOOK (Human et al., 2013) and Cantwell (1970).

Although yeast and Nosema spores reflect light differently in regular light microscopy, the use of phase contrast microscopy will avoid any misidentification (see section 2.2.2.1).

\subsubsection{Individual bees or pooled samples}

To determine the degree of infection in colonies from pooled samples of bees, the required precision of the diagnosis should first be determined (see section 2.1.1.2).

1. Measure $1 \mathrm{ml}$ of water per bee in the pooled sample.

2. Grind the required number of bees, their abdomen or ventriculus (see section 2.2.1.3.) thoroughly in water (1/3 of the measured amount) in a mortar with a pestle.

3. Add the remaining water and mix thoroughly.

4. Add a small droplet to a haemocytometer and allow spores to settle before counting (see the miscellaneous methods paper of the BEEBOOK (Human et al., 2013).

By examining infection in each bee in a sample, the proportion of infected bees can be determined. For N. apis, this is a better measurement than the average spore count per bee in a pooled 
sample (pool of individual bees), if the objective is to measure the influence of infection on honey yield (Fries et al., 1984). To determine the proportion of infected bees within a colony, individual bees must be examined.

1. Use $1 \mathrm{ml}$ of water per bee. If other amounts of water are used it is necessary that the dilution factor is stated. Depending on the content of the bees' intestine with sometimes massive pollen amounts, dilution may be necessary to actually see the spores in light microscopy.

2. Grind each bee, their abdomen or ventriculus separately (see section 2.2.1.3.) thoroughly in water in a mortar with a pestle.

3. Look for the presence of spores in the macerate under a microscope (see section 2.2.2.1.).

The use of 96-well PCR plates with a single bee or abdomen or ventriculus per well for maceration can be useful for high throughput analysis. If using a 96-well plate, a system (manual or automatic) to guarantee that every bee or abdomen is completely macerated to release the spores to be detected needs to be developed.

Nevertheless, there is a highly significant and positive correlation between the proportion of infected bees and average spore counts per bee. Thus, under most circumstances, the less labour intensive use of pooled samples can be used, rather than determining the infection status of at least 59 individual bees (see section 2.1.1.2. and the statistics paper of the BEEBOOK (Human et al., 2013)).

Use of dead bees from the floor board of live colonies should be avoided, since the correlation with the health status of the live bees is too low (Fries et al., 1984).

It remains to be determined whether the relations described here are the same for $N$. ceranae.

\subsubsection{Parts to examine}

Although molecular evidence of $N$. ceranae DNA in other tissues than the ventriculus have been described, no spore production has been demonstrated outside the epithelial cells of the ventriculus for either of the two microsporidians concerned (Chen et al., 2009; Bourgeois et al., 2012). Thus, for spore counts, the ventriculus is ideal since the amount of surplus debris is low compared to using the entire abdomen or the whole bee in mash preparations.

Dissecting the ventriculus:

With some training, it is easy to pull the ventriculus out from $\mathrm{CO}_{2}$ immobilized bees (see the section on anesthetising bees in the BEEBOOK paper on miscellaneous research methods (Human et al., 2013)) using forceps.

1. Grip over the $A 7$ abdominal dorsal and ventral segments with the forceps

2. Hold the abdomen in the other hand

3. Slowly pull apart; the posterior portion of the alimentary canal comes out, sometimes with, sometimes without, the honey sac attached to the anterior end of the ventriculus (Fig. 1).

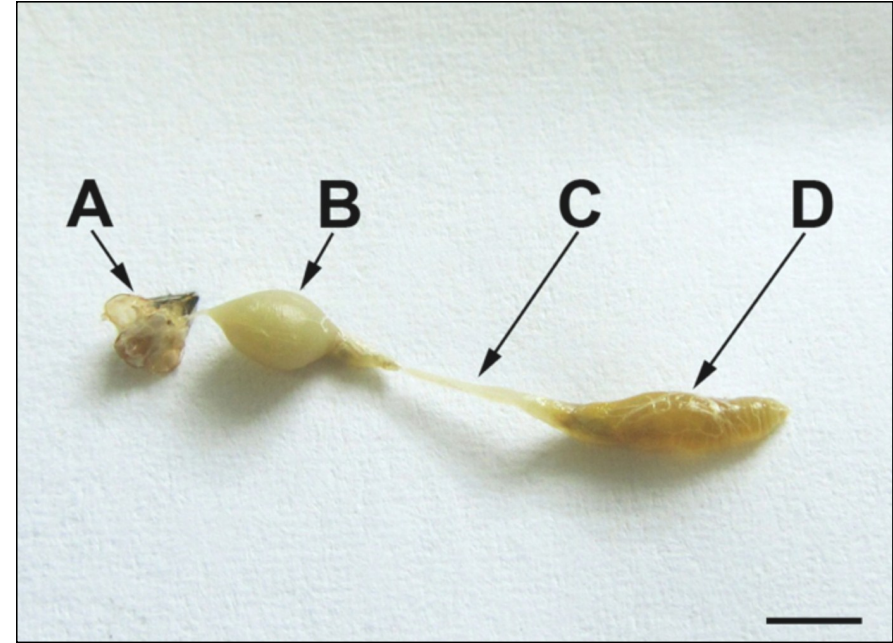

Fig. 1. Posterior section of the worker honey bee alimentary canal and sting apparatus: $\mathrm{A}=$ sting apparatus; $\mathrm{B}=$ rectum; $\mathrm{C}=$ small intestine; and $D=$ ventriculus (midgut). Line $=2 \mathrm{~mm}$ (Dade, 2009).

It should be noted that this procedure is difficult to perform on bees that have been frozen and thawed.

Because of the labour involved, the use of the ventriculus for spore counts is generally more suitable for laboratory cage experiments. For field investigations of colonies, it is recommended to use samples of whole bees, or abdomens of adult bees.

\subsubsection{Nosema species identification}

\subsubsection{Light microscopy (LM)}

A compund microscope using $400 \mathrm{X}$ magnification is sufficient for observing Nosema spp. spores in macerated bee preparations. Use of phase contrast light microscopy facilitates distinguishing spores of microsporidia from yeast or other particles.

Although the differences in spore size between $N$. ceranae and $N$. apis are not immediately apparent in light microscopy, there is a consistent difference. Spores of $N$. ceranae are clearly smaller compared to spores of $N$. apis. Fresh, unfixed spores of $N$. apis measure approximately 6 × $3 \mu \mathrm{m}$ (Zander and Böttcher, 1984); whereas, fresh spores of $N$. ceranae measure approximately $4.7 \times 2.7 \mu \mathrm{m}$ (Fries et al., 1996) (Fig. 2). Although there is a slight overlap, with the smallest $N$. apis spores being smaller than the largest $N$. ceranae spores, the average spore size of $N$. apis is approximately $1 \mu \mathrm{m}$ larger in length (Fig. 2).

In contrast to spores of $N$. apis, the spores of $N$. ceranae are often slightly bent, and appear less uniform in shape compared to N. apis spores (Fries et al., 1996; Fig. 2). Although the difference in the size of spores between these species is clear, it may still be difficult to detect the difference in routine diagnosis of infected bees using light microscopy. This is particularly true because mixed infections of both species can occur (Chen et al., 2009), even in individual bees (Burgher-MacLellan et al., 2010).

Because of their light refractive properties, spores of Nosema spp. are easily seen without contrast colouring in the light microscope in 


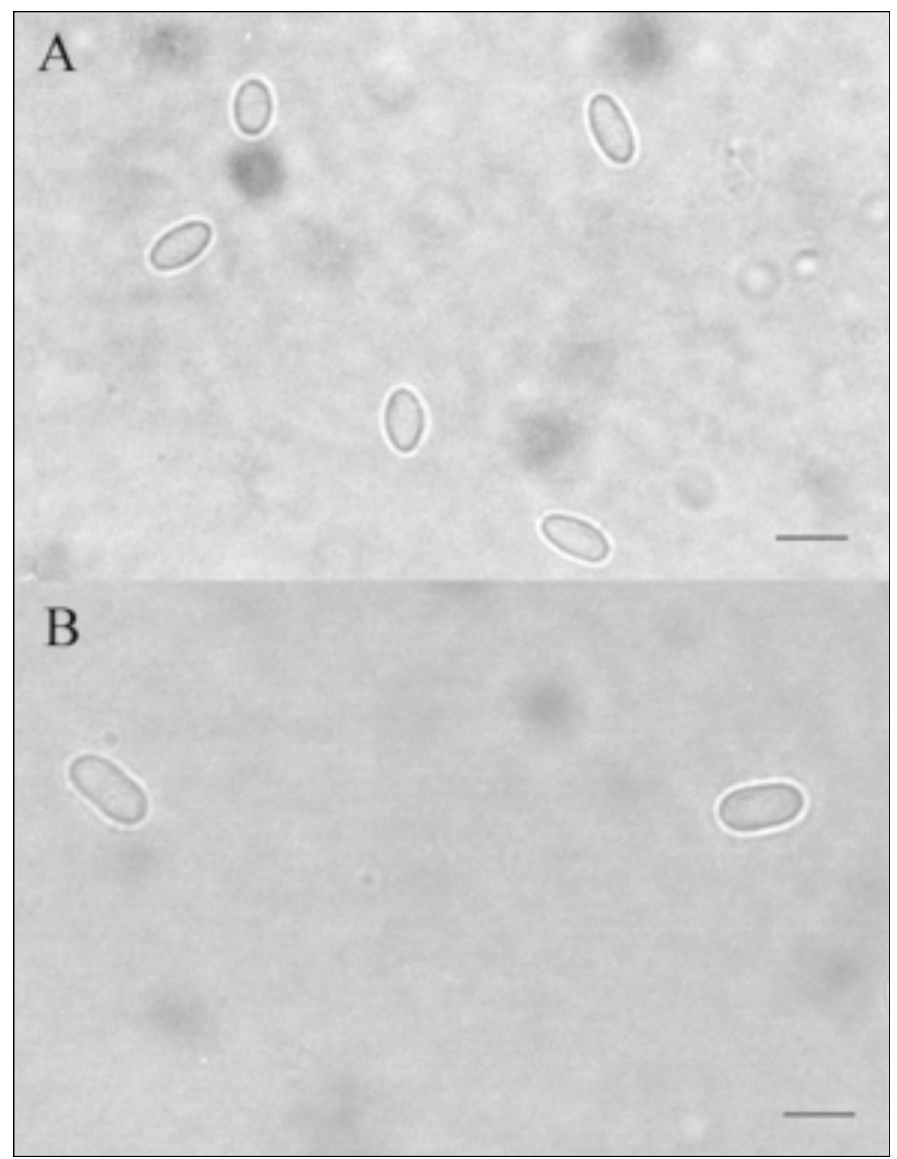

Fig. 2. Spores of Nosema ceranae (A) and Nosema apis (B) in light microscopy squash preparations. Bars $=5 \mathrm{~mm}$. From Fries et al., 2006.

water squash preparations at 200-400 X magnifications. Methanolfixed smears contrast coloured using Giemsa staining is the standard technique for microsporidians and is described in section 2.2.2.1.1. However, the nuclei are not revealed because of the staining of the spore contents. Giemsa staining can be useful to visualize infection in tissue preparations. Another method to identify Nosema species with LM is to mount sections of material embedded for electron microscopy (section 2.2.2.2) for light microscopy after contrast colouring with toluidine blue (section 2.2.2.1.2). For a further range of colouring techniques for microsporidians see Vavra and Larsson (1999).

\subsection{Giemsa staining}

Giemsa's stain stock solution is obtained from commercial sources. The prepared staining solution is prepared fresh by diluting the stock solution 1:9 using PBS buffer ( $\mathrm{pH} 7.4$ ).

1. Apply smear onto microscope slide

2. Allow to air dry

3. Flood with $95 \%$ methanol for 5 minutes, then pour off

4. Flood with $10 \%$ buffered Giemsa (pH7.4) for 10 minutes

5. Wash carefully using tap water

6. Dry using filter paper

\subsection{Toluidine staining}

Toluidine staining (Fig. 3) is applied to semi thin sections of epoxy embedded tissue (section 2.2.2.2). The stained sections can be used to determine the area of interest for further processing, but also for LM observations. Toluidine stock solution is obtained from commercial sources.

The $1 \%$ toluidine blue and $2 \%$ borate in distilled water needed is obtained by mixing:

- $1 \mathrm{~g}$ toluidine blue 0

- $2 \mathrm{~g}$ sodium borate (borax)

- $100 \mathrm{ml}$ distilled water

1. Dissolve the sodium borate in the water

2. Add the toluidine blue powder

3. Stir until dissolved

4. Filter the stain solution (use syringe filter) before use Note: The borax makes the stain alkaline so it will help penetrating to the epoxy sections

\section{Staining process}

1. Cut semi-thin sections at $0.5-1.0 \mu \mathrm{m}$

2. Transfer sections to a drop of distilled water on a glass slide

3. Dry sections on a glass slide on a slide warmer or over a $40 \mathrm{~W}$ lamp

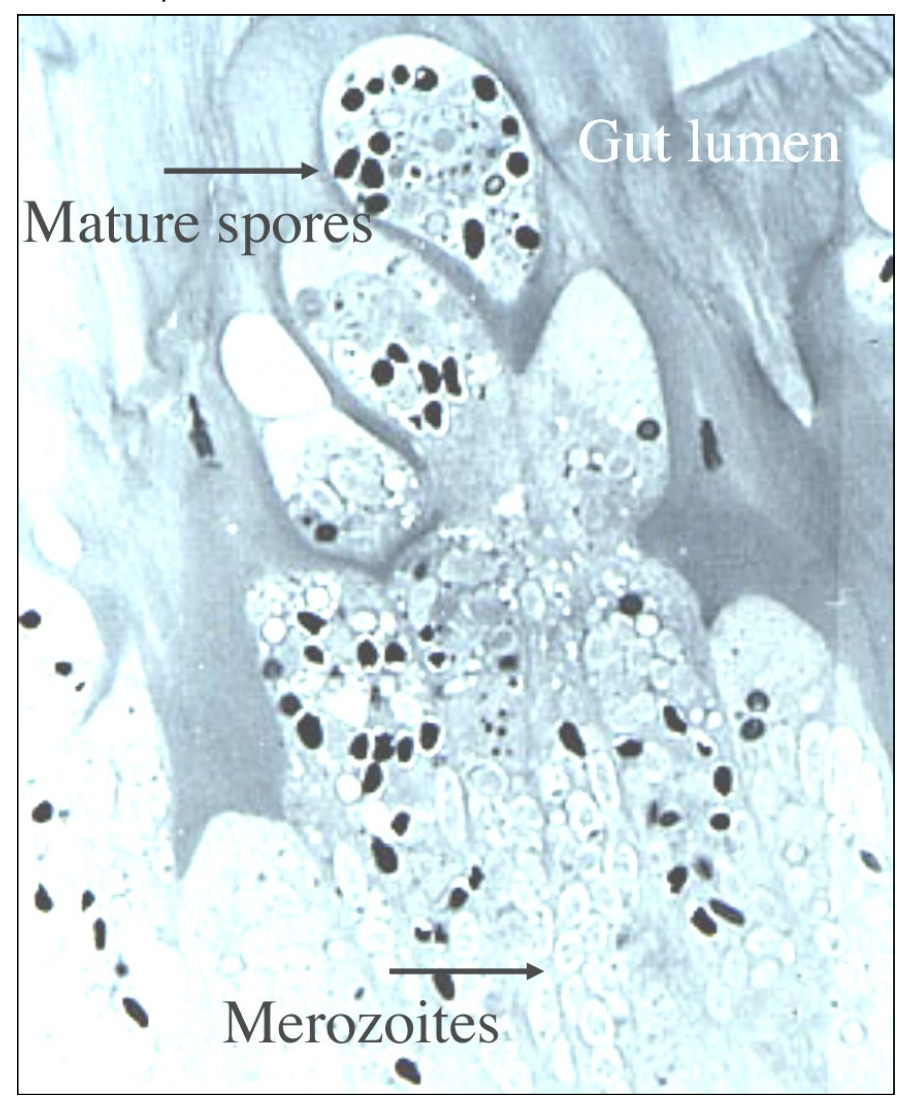

Fig. 3. Toluidine staining of a semi thin section of epoxy embedded ventricular tissue. 


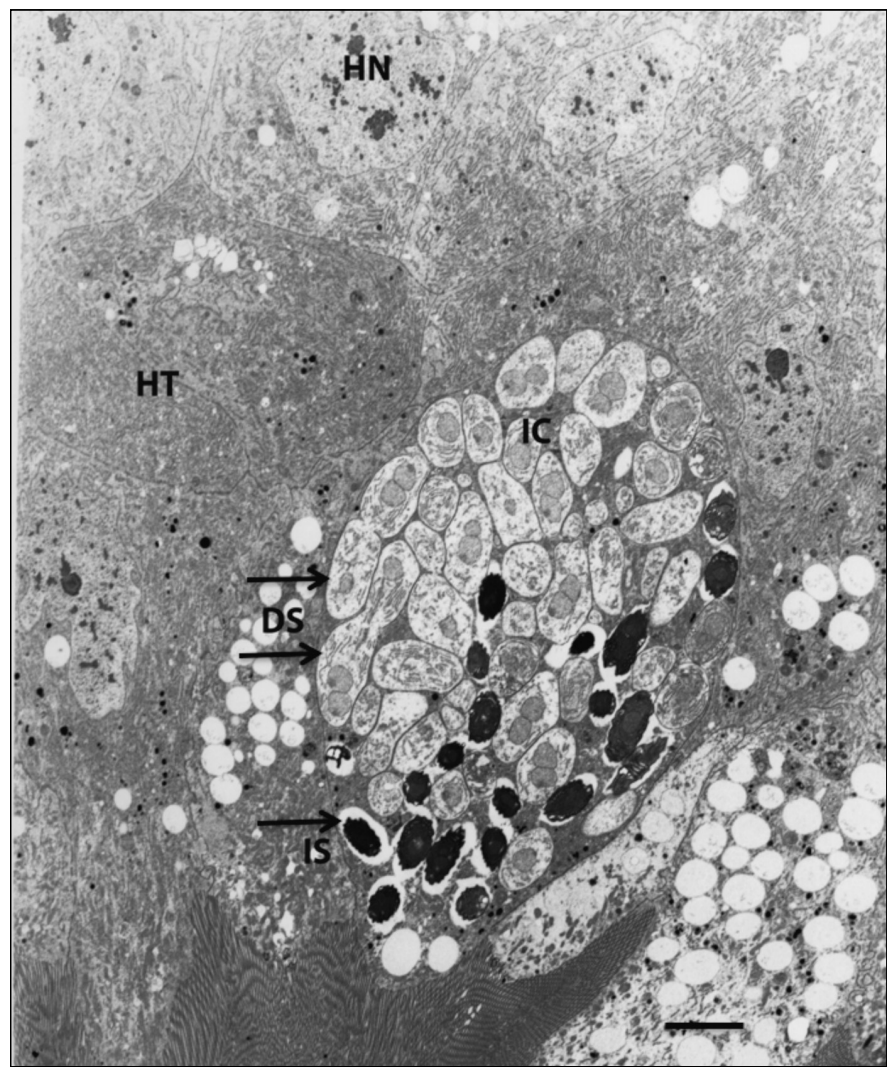

Fig. 4. Transmission electron micrograph of $N$. ceranae infected tissue: host nucleus (HN); healthy tissue (HT); infected cell (IC); dividing stages (DS); immature spore (IS). Bar $=10 \mathrm{~mm}$.

4. Cover section with staining solution (with the heat source still on) for 1-2 minutes

5. Rinse off excess stain with distilled water and air dry

\subsubsection{Transmission electron microscopy (TEM)}

Several fixation procedures are available for studies of microsporidia infections. The following methodology has been widely used with good results for both N. apis (Fries, 1989; Fries et al., 1992) and N. ceranae (Fries et al, 1996, Fig. 4):

1. Prefix tissue specimens for transmission electron microscopy using $4 \%$. glutaraldehyde (v/v) in $0.067 \mathrm{M}$ cacodylate buffer, $\mathrm{pH} 7.4$, for 3 days to three weeks.

2. Keep material refrigerated $\left(+7^{\circ} \mathrm{C}\right)$ during prefixation.

3. Wash in cacodylate buffer.

4. Post fix for 2 hours in $2 \%$ OsO4 (w/v) in 0.1 M S-colloidine buffer.

5. Dehydrate through ethanol series at room temperature:

5.1. $5 \mathrm{~min}$. in $30 \% \mathrm{EtOH}$,

5.2. 5 min. in $50 \% \mathrm{EtOH}$,

5.3. $5 \mathrm{~min}$. in $75 \% \mathrm{EtOH}$,

5.4. $5 \mathrm{~min}$. in $95 \% \mathrm{EtOH}$,

5.5. $3 \times 10 \mathrm{~min}$. in $100 \% \mathrm{EtOH}_{\text {, }}$

5.6. $3 \times 10 \mathrm{~min}$. in $100 \%$ propylene oxide.

6. Embed in epoxy resin (Agar 100) by routine procedures for electron microscopy.
The number of polar filament coils is one tool that helps to differentiate between species of Nosema (Burges et al., 1974). In $N$. ceranae, the number of filament coils varies between 20 and 23 in mature spores (Fries et al., 1996), whereas the number of polar filament coils in spores of $N$. apis is always larger and often more than 30 (Fries, 1989). The immature spores, where the filament is still developing, can be distinguished from mature spores on the less developed spore wall.

\subsubsection{Molecular detection of Nosema spp. (N. apis, N. ceranae and N. bombi)}

In addition to the microscopic techniques described above, various molecular methods have been developed for the detection and identification of Nosema spp. because such molecular methods are more sensitive and species specific (Klee et al., 2006; 2007). As a consequence, it is possible to confirm the presence of Nosema (and other disease organisms) in bees using molecular techniques even when visual detection suggests its absence. Care must be exercised, though, in interpretation of results from molecular detection. Nosema may be detected molecularly in a bee, though very few spores are present in the bee and the pathogen has little or no impact on its host. In addition, vegetative forms of Nosema as well as spores can be detected using molecular methods, whereas only spores can be detected using visual methods. A further advantage of molecular methods, is that their extreme sensitivity of detection may provide insights into hitherto unknown modes of transmission of pathogens.

The molecular techniques developed for detection of Nosema spp. in bees (i.e. N. apis, Nosema bombi, found to date only in bumble bees, and $N$. ceranae) are usually PCR-based (i.e. uniplex or multiplex PCR, PCR-RFLP, qPCR; see the BEEBOOK paper on molecular methods (Evans et al., 2013), and a wide range of species-specific PCR primer sets for these Nosema species can be found in the literature (Table 1). A test of the specificity and detection limits of nine of these primer sets suggests that some of them may lack specificity or exhibit low sensitivity (Erler et al., 2011). In addition, the use of different molecular methods or conditions across laboratories can lead to inconsistencies. For this reason, it is recommended that PCR-based screening protocols be optimized and adjusted to fit each individual laboratory's conditions, research and monitoring questions. To allow comparisons across laboratories, we recommend analysis of the same homogenates of infected bees in each laboratory to account for differences in sensitivity, or for threshold sensitivities of detection to be reported per laboratory in terms of minimum number of spores per bee that can be detected by molecular markers.

Whilst most primers are designed for conventional $P C R$, real time PCR (qPCR or quantitative PCR, see the BEEBOOK paper on molecular methods (Evans et al., 2013)) primers and protocols for quantification of $N$. ceranae and $N$. apis have also been developed (Table 1 ), including primers that quantify both species in one reaction (Martín-Hernández et al., 2007). As for standard PCR, primer sets for 
Table 1. List of primer sets available for the detection of Nosema spp. in bees by PCR.

\begin{tabular}{|c|c|c|c|c|c|c|c|c|}
\hline \multirow[b]{2}{*}{ Name } & \multirow[b]{2}{*}{ Source } & & \multirow[b]{2}{*}{ Primer sequence $\left(5^{\prime}-3^{\prime}\right)$} & \multirow[b]{2}{*}{ locus } & \multirow[b]{2}{*}{ use } & \multicolumn{3}{|c|}{ Fragment size (bp) } \\
\hline & & & & & & N.a. & N.b. & N.c. \\
\hline 218MITOC & Martín-Hernández et al. 2007 & $\begin{array}{l}\text { fwd } \\
\text { rev }\end{array}$ & $\begin{array}{l}\text { CGGCGACGATGTGATATGAAAATATTAAA } \\
\text { CCCGGTCATTCTCAAACAAAAAACCG }\end{array}$ & SSU rRNA & qPCR & & & $218-219$ \\
\hline 321APIS & Martín-Hernández et al. 2007 & $\begin{array}{l}\text { fwd } \\
\text { rev }\end{array}$ & $\begin{array}{l}\text { GGGGGCATGTCTTTGACGTACTATGTA } \\
\text { GGGGGGCGTITAAAATGTGAAACAACTATG }\end{array}$ & SSU rRNA & qPCR & 321 & & \\
\hline BOMBICAR & Plischuk et al. 2009 & $\begin{array}{l}\text { fwd } \\
\text { rev }\end{array}$ & $\begin{array}{l}\text { GGCCCATGCATGTTITTGAAGATTATTAT } \\
\text { CTACACTTTAACGTAGTTATCTGCGG }\end{array}$ & SSU rRNA & PCR & & 101 & \\
\hline ITS & Klee et al. 2006 & $\begin{array}{l}\text { fwd } \\
\text { rev }\end{array}$ & $\begin{array}{l}\text { GATATAAGTCGTAACATGGTTGCT } \\
\text { CATCGTTATGGTATCCTATTGATC }\end{array}$ & ITS region & PCR & 120 & 120 & 120 \\
\hline N.b.a & Erler et al. 2011 & $\begin{array}{l}\text { fwd } \\
\text { rev }\end{array}$ & $\begin{array}{l}\text { TGCGGCTTAATTTGACTC } \\
\text { GGGTAATGACATACAAACAAAC }\end{array}$ & SSU rRNA/ITS & PCR & & 511 & \\
\hline Nbombi-SSU-J & Klee et al. 2006 & $\begin{array}{l}\text { fwd } \\
\text { rev }\end{array}$ & $\begin{array}{l}\text { CCATGCATGTTITGAAGATTATTAT } \\
\text { CATATATITTAAAATATGAAACAATAA }\end{array}$ & SSU rRNA & PCR & & 323 & \\
\hline NOS & Higes et al. 2006 & $\begin{array}{l}\text { fwd } \\
\text { rev }\end{array}$ & $\begin{array}{l}\text { TGCCGACGATGTGATATGAG } \\
\text { CACAGCATCCATTGAAAACG }\end{array}$ & SSU rRNA & PCR & 240 & & 252 \\
\hline NosA & Webster et al. 2004 & $\begin{array}{l}\text { fwd } \\
\text { rev }\end{array}$ & $\begin{array}{l}\text { CCGACGATGTGATATGAGATG } \\
\text { CACTATTATCATCCTCAGATCATA }\end{array}$ & SSU rRNA & PCR & 209 & & \\
\hline SSU-res & Klee et al. 2007 & $\begin{array}{l}\text { fwd } \\
\text { rev }\end{array}$ & $\begin{array}{l}\text { GCCTGACGTAGACGCTATTC } \\
\text { GTATTACCGCGGCTGCTGG }\end{array}$ & SSU rRNA & PCR & 402 & 402 & 402 \\
\hline NaFor & Forsgren and Fries 2010 & fwd(a) & CTAGTATATTTGAATATTTGTTTACAATGG ${ }^{\mathrm{b}}$ & LSU rRNA & qPCR & 278 & & \\
\hline NcFor & & fwd(c) & TATTGTAGAGAGGTGGGAGATT & & & & & 316 \\
\hline UnivRev & & Urev & GTCGCTATGATCGCTTGCC & & & & & \\
\hline Nosema & Chen et al. 2008 & $\begin{array}{l}\text { fwd } \\
\text { rev }\end{array}$ & $\begin{array}{l}\text { GGCAGTTATGGGAAGTAACA } \\
\text { GGTCGTCACATTTCATCTCT }\end{array}$ & SSU-rRNA & generic & 208 & & 212 \\
\hline N. ceranae & Chen et al. 2008 & $\begin{array}{l}\text { fwd } \\
\text { rev }\end{array}$ & $\begin{array}{l}\text { CGGATAAAAGAGTCCGTTACC } \\
\text { TGAGCAGGGTTCTAGGGAT }\end{array}$ & SSU-rRNA & PCR & & & $250^{\mathrm{a}}$ \\
\hline N. apis & Chen et al. 2008 & $\begin{array}{l}\text { fwd } \\
\text { rev }\end{array}$ & $\begin{array}{l}\text { CCATTGCCGGATAAGAGAGT } \\
\text { CACGCATTGCTGCATCATTGAC }\end{array}$ & SSU-rRNA & PCR & $401^{\mathrm{a}}$ & & \\
\hline Nos-16S & Stevanovic et al. 2011 & $\begin{array}{l}\text { fwd } \\
\text { rev }\end{array}$ & $\begin{array}{l}\text { CGTAGACGCTATTCCCTAAGATT } \\
\text { CTCCCAACTATACAGTACACCTCATA }\end{array}$ & SSU rRNA & PCR & 488 & & 488 \\
\hline Mnceranae-F & This report & fwd & CGTTAAAGTGTAGATAAGATGTT & SSU rRNA & PCR & & & \\
\hline Mnapis-F & & fwd & GCATGTCTTTGACGTACTATG & & & & & 143 \\
\hline Mnbombi-F & & fwd & TTTATTTTATGTRYACMGCAG & & & & 171 & \\
\hline Muniv-R & & Urev & GACTTAGTAGCCGTCTCTC & & & 224 & & \\
\hline SSUrRNA-f1b & Tay et a/ 2005 & Ufwd & CACCAGGTTGATTCTGCCT & SSU rRNA & generic & & ca. & \\
\hline SSUrRNA-r1b & & Urev & TGTTCGTCCAGTCAGGGTCGTCA & & & & & \\
\hline
\end{tabular}

ITS: internal transcribed spacer region; SSU: small subunit rRNA (16S rRNA); N.a.: Nosema apis, N.b.: Nosema bombi, N.c.: Nosema ceranae. ${ }^{a}$ Fragment size could not be verified. ${ }^{b}$ Sequence modified to complement original GenBank entry U97150.

Use: PCR, standard PCR (for the detection of different Nosema spp.); qPCR, for quantitative or real time PCR (for the quantification of different Nosema spp.) and standard PCR (for the detection of different Nosema spp.); generic, primers amplify all known Nosema spp. or all Microsporidia without differentiating among species.

qPCR need to be tested in each laboratory for sensitivity and reliability (see also Bourgeois et al., 2010; Burgher-MacLellan et al., 2010; Hamiduzzaman et al., 2010; Traver and Fell, 2012 and the molecular paper of BEEBOOK by Evans et al., 2013).

Here we report the use of a multiplex PCR-based method that is able to detect and differentiate simultaneously the three Nosema species of high prevalence in European bee populations ( $N$. apis, $N$. bombi and N. ceranae) using genomic DNA. Microsporidia from genera other than Nosema are known from bees, where they can be very abundant (see Paxton et al., 1997; Li et al., 2012). To capture all of these Microsporidia, it is advisable to PCR amplify microsporidian DNA using 'generic' primers (see Table 1) and then sequence PCR products, which can be laborious and expensive. Here we present a much faster and cheaper method in which we combined multiple primers based on the $16 \mathrm{~S}$ ribosomal rRNA gene into a single reaction to simultaneously detect $N$. apis, $N$. bombi and $N$. ceranae in bees.

\subsection{Nosema DNA extraction}

DNA extraction can be performed from specific tissue (e.g. ventriculus, rectum, fat body), subdivided bee sections (e.g. metasoma), whole bees, or homogenates from pooled samples (see the BEEBOOK paper on bee anatomy and dissection (Carreck et al., 2013)).

Nosema DNA extraction from bee homogenates:

1. Crush fresh or flash frozen tissue to generate a homogeneous homogenate of bee/bee guts. For example,

1.1. place a maximum of 30 bees in a filter grinding bag (e.g. extraction bags from BIOREBA AG, Switzerland).

1.2. Add $0.5 \mathrm{ml}$ (DNAase/RNAase free) $\mathrm{ddH}_{2} \mathrm{O}$ per bee.

1.3. homogenize the mixture using a homogenizer (e.g. Homex6 from BIOREBA AG; Switzerland).

1.4. Flash-freeze in liquid nitrogen is possible prior to homogenization to aid in mechanically breaking open cells.

1.5. Crush the sample. 
Without access to a robot, one can use a pestle to crush the bee tissue.

2. Transfer $100 \mu \mathrm{l}$ of the liquid homogenate into a microcentrifuge tube and centrifuge for $3 \mathrm{~min}$ at $16,100 \mathrm{~g}$ to precipitate the microsporidia and other cellular material.

3. Discard the supernatant.

4. Freeze the pellet by using liquid nitrogen.

5. Crush using a pestle until pulverized (in order to break open Nosema spore walls).

6. Repeat steps 4 and 5 two or three times so that Nosema DNA goes into solution.

7. Use the DNeasy ${ }^{\circledR}$ Plant Mini kit protocol (Qiagen) following the Mini protocol for plant tissue to extract DNA from the homogenate.

Other non-proprietary DNA extraction protocols (e.g. those using phenol/chloroform; chelex resin; Tay et al. 2005) were used with poor success, possibly because bee guts contain plant secondary compounds and tissue may be in a state of decay due to poor preservation. Research on other extraction techniques (e.g. using CTAB) is needed to provide cheaper yet efficient methods for the extraction of Nosema DNA from bees.

8. Complete the final elution step in $100 \mu \mathrm{l}$ of $0.01 \mathrm{M}$ Tris $(\mathrm{pH} 7.5)$ buffer.

The same Qiagen protocol can also be implemented in the QiaCube (Qiagen) for automated DNA extraction.

\subsection{Multiplex PCR for detection of Nosema and} differentiation between $N$, apis, $N$, bombi and $N$, ceranae For multiplex PCR amplification of partial 16S rRNA (= SSU rRNA) gene fragments, we recommend the following primer combination, though others from Table 1 (standard or qPCR primers) may be more suitable for different purposes and in different laboratories:

Primers were designed based on alignment of all available sequence data in GenBank of the 16S rRNA gene from N. apis, N. bombiand N. ceranae.

Mnapis-F forward primer: 5'-GCATGTCTTTGACGTACTATG-3' Mnbombi-F forward primer: 5'-TTATTTTATGTRYACMGCAG-3' Mnceranae-F forward primer: $5^{\prime}$ - CGTTAAAGTGTAGATAAGATGTT-3' Muniv-R: reverse primer: 5'- GACTTAGTAGCCGTCTCTC-3'

Note that the Mnbombi-F primer contains variable sites to account for the sequence diversity observed for this species.

\section{PCR product size:}

- for N. ceranae: $143 \mathrm{bp}$

- for N. bombi: 171 bp

- for N. apis. 224 bp

\subsection{PCR reaction mix}

- $1 \mu \mathrm{l}$ of DNA extract (ca. $1 \mathrm{ng}$ )

- $0.5 \mathrm{U}$ of GoTaq ${ }^{\circledR}$ polymerase (Promega)

- $2 x \mathrm{GoTaq}^{\circledR}$ reaction buffer $\left(3 \mathrm{mM} \mathrm{MgCl}_{2}\right.$ final concentration, Promega)

- $\quad 0.3 \mathrm{mM}$ of each dNTP (dNTP mix from Promega)

- $0.4 \mu \mathrm{M}$ of Mnceranae $\mathrm{F}$

- $0.4 \mu \mathrm{M}$ of MnapisF

- $0.5 \mu \mathrm{M}$ of Mnbombi-F

- $0.5 \mu \mathrm{M}$ of Muniv-R

- $\mathrm{H}_{2} \mathrm{O}$ as required, to make up to a $10 \mu \mathrm{l}$ total volume.

Amplification is carried out on a thermocycler (e.g. TProfessional Biometra) using the following conditions:

1. Initial denaturation step of $95^{\circ} \mathrm{C}$ for $2 \mathrm{~min}$,

2. 35 cycles of $\left(95^{\circ} \mathrm{C}\right.$ for $30 \mathrm{~s}, 55^{\circ} \mathrm{C}$ for $30 \mathrm{~s}$ and $72^{\circ} \mathrm{C}$ for $60 \mathrm{~s}$ ),

3. Final extension step of $72^{\circ} \mathrm{C}$ for $5 \mathrm{~min}$.

Each laboratory might have to optimise de novo primers, protocols and PCR conditions.

\subsection{Visualization}

1. Resolve the amplification products

2. Visualize in a QIAxcel electrophoresis system with a QIAxcel DNA high resolution kit (QIAGEN)

3. Analyse using the QIAxcel ScreenGel software (v1.0.0.0).

The resolution method is:

- OM700 (3-5 bp)

- QX DNA Size Marker: 25 bp-450 bp,

- QX Alignment Marker: 15 bp/400 bp. Typical results are presented in Fig. 5.

As a cheaper alternative, PCR products can be resolved in a 1-2\% agarose gel with suitable size marker and then visualised by staining with ethidium bromide and photographing on $\mathrm{a} u / \mathrm{v}$ transilluminator (see the BEEBOOK paper on molecular methods (Evans et al., 2013).

\subsection{Controls}

Attention needs to be given to the use of controls when undertaking DNA extractions and PCR amplifications to avoid false positives (detection of a band of the appropriate size when a Nosema species was not present) and false negatives (absence of a band of the appropriate size because of poor extraction or poor PCR set-up despite a Nosema species being present). We recommend using newly emerged honey bees as 'negative controls' because such bees are not infected with $N$. apis or $N$. ceranae at emergence although for 


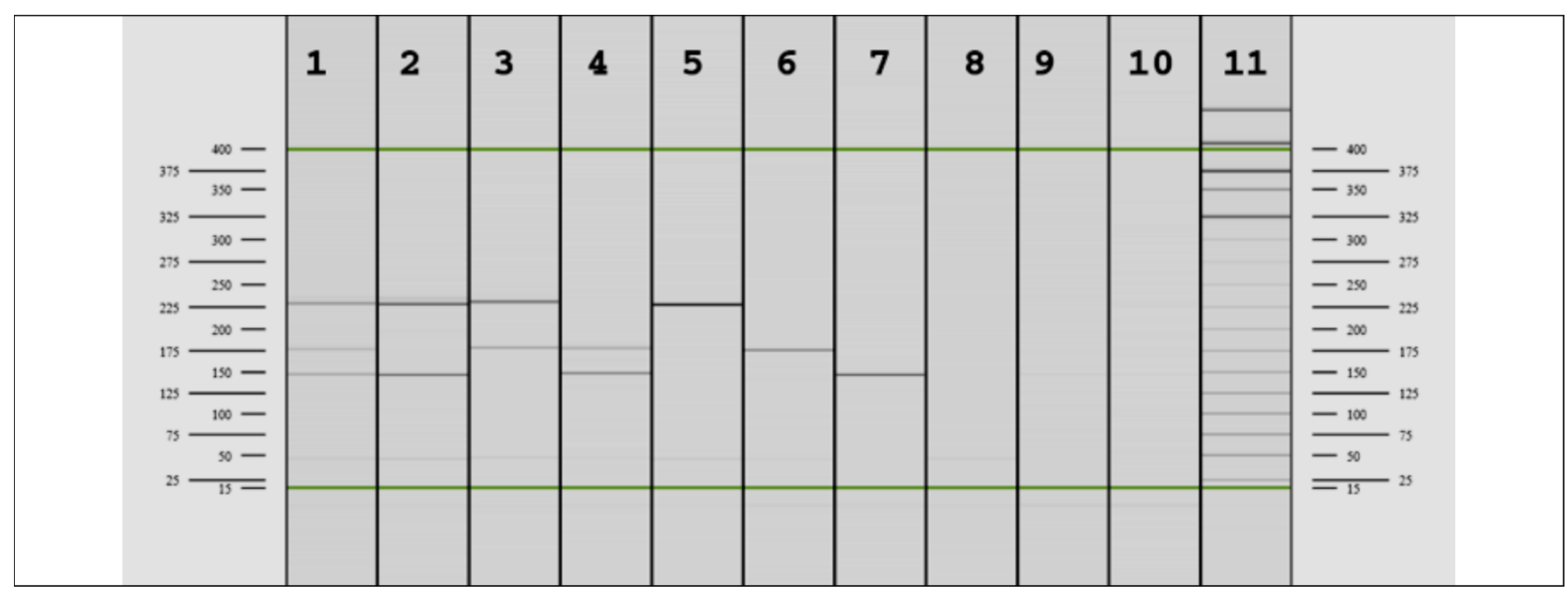

Fig. 5. PCR products of Nosema-infected bees from which DNA has been extracted and amplified by PCR using the multiplex primer mix Mnapis F, Mnbombi F, Mnceranae F and Muniv-R to reveal N. apis, N. bombi and N. ceranae: 1. N. apis + N. bombi+ N. ceranae; 2. N. apis + N. ceranae; 3. N. apis + N. bombi; 4. N. ceranae + N. bombi; 5. N. apis, 6. N. bombi; 7. N. ceranae; 8. Control, no template; 9. Apis mellifera negative control; 10. Bombus spp. negative control; 11. size ladder.

\section{N. ceranae vertical transmission of infection has recently been} suggested (Traver and Fell, 2012). Greater care needs to be given to negative controls for $N$. bombi in bumble bees as this microsporidian may be transmitted transovarially from queen to offspring (Rutrecht and Brown, 2008). For positive controls, it is best to use adult bees that have been experimentally infected with spores and to confirm visually that spores are present in the homogenate before DNA extraction.

\subsection{Realtime PCR for quantification of $N$, apis and N. ceranae}

Molecular quantification of $N$. apis and $N$. ceranae allows both relative quantification of the two Nosema species or their absolute quantification per bee or per sample, which can be of considerable interest for studies of the interactions between these two pathogens. However, molecular quantification requires use of a real-time PCR machine; these machines are currently relatively expensive and they require calibration with dilution series of $N$. apis and $N$. ceranae to generate accurate quantification.

Several realtime PCR machines are on the market, each employing different fluorophore chemistries for molecular quantification. Here we present a method based on Forsgen and Fries (2010) that uses a BioRad MiniOpticon real-time PCR machine and EvaGreen chemistry for quantification as it has functioned well in several laboratories.

\subsection{PCR reaction mix}

PCRs use a $20 \mu \mathrm{l}$ final volume and should be set up as follows for the quantification of either $N$. apis or $N$. ceranae using primers from Forsgen and Fries (2010) in Table 1. Set up one mastermix as below for quantification of $N$. apis for each sample and set up another mastermix as below for quantification of $N$. ceranae for each sample, using either NaFor or NcFor respectively.

- SsoFast ${ }^{\mathrm{TM}}$ EvaGreen ${ }^{\circledR}$ Supermix (BioRad) $1 \mathrm{x}$

- NaFor or NcFor primer $0.4 \mu \mathrm{M}$

- UnivRev primer $0.4 \mu \mathrm{M}$

- $\mathrm{H}_{2} \mathrm{O}$ $6.4 \mu \mathrm{l}$

- Sample DNA extract $2 \mu \mathrm{l}($ ca. $2 \mathrm{ng}$ DNA)

\subsection{Quantification}

Amplification and data acquisition are carried out in a MiniOpticon ${ }^{\circledR}$ (Bio-Rad) real-time PCR machine using the following program:

1. Initial enzyme activation step:
a. $98^{\circ} \mathrm{C}$ for $15 \mathrm{~min}$

2. Followed by 40 cycles of:

a. denaturation at $98^{\circ} \mathrm{C}$ for $5 \mathrm{sec}$

b. annealing/extension at $63^{\circ} \mathrm{C}$ for $10 \mathrm{sec}$

c. melt curve analysis from $65-95^{\circ} \mathrm{C}$ (in $0.5^{\circ} \mathrm{C}$ increments) $10 \mathrm{sec} / \mathrm{step}$

Specificity and the absence of non-specific amplification are determined based on the melting temperature $(\mathrm{Tm})$ of the amplified products (see also molecular methods paper of the BEEBOOK (Evans et al., 2013)).

\subsection{Controls}

For controls, the criteria and warnings provided previously for standard PCR for the detection of Nosema spp. are applicable (section 2.2.2.3.2.3). For quantification, $N$. apis and $N$. ceranae recombinant amplicons should be used as external standards. Set up 
a standard curve using serial dilutions of recombinant target DNA fragments ranging from $10^{-2}$ to $10^{-8}$ and include them as quantification standards in every PCR run (see also the BEEBOOK paper on molecular methods (Evans et al., 2013)).

\subsubsection{Standardising cage trials}

This section contains information on methodologies specifically for performing laboratory investigations of the adult European honey bee-Nosema system. Additional details on general methodologies for maintaining European honey bees in the laboratory are described by Williams et al. (2013) in the laboratory cages paper of the BEEBOOK.

\subsubsection{Source of bees}

General details on selecting bees and colonies for experiments can be found in the BEEBOOK papers by Williams et al. (2013) and Human et al. (2013). Details specific to Nosema investigations are discussed here. See the BEEBOOK paper on maintaining bees in cages (Williams et al., 2013) for information on how to obtain honey bees for experiments.

For every experiment state:

1. The subspecies of European honey bee used because of there may be genetic variation for disease resistance (Evans and Spivak, 2010).

2. The time of year the experiment was performed because bee physiology can differ seasonally, in particular between summer and winter (Fluri et al., 1977), but also when brood rearing declines (Amdam et al., 2009).

Further considerations:

1. Cage replicates should be performed during the same season to allow for easier comparison of data.

2. Bees from multiple colonies should be used to ensure that the particular question being asked is relevant to honey bees in general (see Human et al. (2013) and Williams et al. (2012))

3. Use a sufficient number of replicate cages per treatment (see Human et al. (2013) and Williams et al. (2012)).

Bees from all colonies should be homogenized among cages to eliminate effect of 'colony', thereby leaving only 'cage' as a random factor.

\subsection{Source colonies}

Colonies should be 'healthy', and quantitatively and qualitatively assessed, as described above and elsewhere in the BEEBOOK (the paper on estimating colony strength (Delaplane et al., 2013)), to demonstrate zero or low infection of major pathogens or parasites, including $N$. apis, N. ceranae (this paper), and the mite Varroa destructor (see the BEEBOOK paper on varroa (Dietemann et al., 2013)). Because Nosema interacts with pesticides (Alaux et al., 2010a), colonies likely to be exposed to high levels of agro-chemicals, such as those pollinating agricultural crops, should not be used. Nosema also interacts with viruses (Bailey et al., 1983; Costa et al., 2011); but because colonies with asymptomatic viral infections are nearly ubiquitously distributed (e.g. Tentcheva et al., 2004; Williams et al., 2009), colonies without symptomatic individuals will suffice. If possible, titre levels of common honey bee viruses, in particular deformed wing and black queen cell viruses, should be quantitatively assayed in bees from potential source colonies, as described by de Miranda et al. (2013) in the virus paper of the BEEBOOK.

\subsection{Age of bees}

The age when honey bees are inoculated with Nosema spores may also influence parasite development and virulence due to changes in honey bee immune response (Amdam et al., 2005) and morphology (Rutrecht et al., 2007) as bees grow older. However, no such influence has been studied for Nosema spp. to our knowledge, and handling of very young bees for spore inoculation may damage the bees and reduce longevity. It is generally advisable to initiate inoculations when the bees are a few days old (2-5 days).

\subsubsection{Type of cages}

Numerous cage designs exist for maintaining honey bees in the laboratory and for performing experiments (see Williams et al. (2013) in the $B E E B O O K)$. Despite this diversity, it is necessary that cages meet basic criteria described by Williams et al. (2013).

- Vital for Nosema studies, cages must be used once and discarded, or sterilized if used multiple times, to prevent contamination by Nosema spores. Multiple-use cages should be made from materials that are easily autoclaveable such as stainless steel and glass because spores of $N$. ceranae in PBS can only be confidently destroyed by exposure to $121^{\circ} \mathrm{C}$ for 30 minutes (Fenoy et al., 2009). Dry sterilisation of wooden cages (i.e., $80^{\circ} \mathrm{C}$ for $1 \mathrm{hr}$.) destroys viability of $N$. apis spores (Cantwell and Shimanuki, 1969); this method is also probably effective for $N$. ceranae, although it remains to be verified.

- To reduce risk of contamination by Nosema spores among individuals differentially treated and maintained in the same incubator, cages should be placed sufficiently apart. If screens or holes are used to provide ventilation, they should face in opposite directions.

Additional materials, such as comb (e.g. Czekońska, 2007) and plastic strips for releasing queen mandibular pheromone (e.g. Alaux et al., 2010a), are sometimes used during laboratory experiments. Although queen mandibular pheromone probably promotes honey bee health and reduces stress of the caged individuals, its effect on Nosema development is not understood and therefore its use should be avoided until our knowledge is improved. 


\subsubsection{Type of food}

Because diet can affect honey bee longevity (Schmidt et al., 1987), immune response to Nosema infection (Alaux et al., 2010b), as well as spore development (Porrini et al., 2011), it is important to carefully consider food provided to experimental bees. Generally, researchers should attempt to maintain their honey bees as healthy as possible.

Honey bees are capable of surviving for long periods of time on $50 \%$ (weight/volume) sucrose solution (Barker and Lehner, 1978); however, to ensure normal development of internal organs and glands (Pernal and Currie, 2000), as well as proper immune response (Alaux et al., 2010b), supplementing a strict carbohydrate diet with protein, and even nutrients such as vitamins and minerals, is recommended for maintaining honey bees in the laboratory. Bee-collected pollen provides an adequate medium for providing protein and nutrients (Brodschneider and Crailsheim, 2010); however, such material may be contaminated with Nosema spores (Higes et al., 2008b) or pesticides (Pettis et al., 2012). Additionally, it is possible that pollen may stimulate N. ceranae development by promoting bee health (Porrini et al., 2011).

Therefore, in addition to ad libitum $50 \%$ (weight/volume) sucrose solution (i.e. $100 \mathrm{~g}$ table sugar dissolved in $100 \mathrm{ml}$ tap water), individuals should be provided with an easily accessible source of multi-floral, radiation sterilised, bee-collected pollen ad libitum as described by Williams et al. (2013) and Human et al. (2013) in the BEEBOOK.

Further studies are needed to investigate the effects of commercial pollen substitutes on Nosema development and individual bee health before they should be considered as a replacement for bee collected pollen.

To sterilize for $N$. apis spores, pollen can be exposed to $\geq 0.2 \times 10^{6}$ rads gamma radiation from cobalt- 60 (Katznelson and Robb, 1962) or heat treated at $49^{\circ} \mathrm{C}$ for 24 hours (Cantwell and Shimanuki, 1969). On the other hand, very little is known about the factors responsible for making $N$. ceranae spores non-viable in bee products. $N$. ceranae will lose viability during freezing (Forsgren and Fries, 2010), but it is more resistant to heat than its congener (Fenoy et al., 2009). It is likely that temperatures and/or exposures higher than required for $N$. apis spore destruction will also render $N$. ceranae spores non-viable. As a result, a combination of heating and freezing pollen may be possible to develop as an alternative to radiation for sterilising bee-collected pollen of Nosema spores. Specific protocols need to be developed for this purpose because to date we only know that one week of freezing kills approximately $80 \%$ of $N$. ceranae spores (Fries, 2010), and we do not know what temperatures will reduce the nutritive value of pollen.

\subsubsection{Incubation conditions}

Researchers should attempt to maintain their experimental bees in optimal conditions for both host and parasite, and should consider the possible effects of growth chamber conditions, as environmental conditions can have a large influence on both host susceptibility and parasite virulence (e.g. Kraus and Velthuis, 1997; Ferguson and Read, 2002; McMullan and Brown, 2005). Although few data exist on the effects of specific temperatures on Nosema parasitism in honey bees, it is clear that intra-host development of both parasites in European honey bees, as well as spore viability, can be affected by temperature (e.g. Malone et al., 2001; Fenoy et al., 2009; Martín-Hernández et al., 2009; Fries, 2010; Higes et al., 2010).

Adult workers should be maintained in complete darkness at $30^{\circ} \mathrm{C}$ and approximately $60-70 \% \mathrm{RH}$ in a growth chamber or incubator with adequate ventilation. A data logger should be used to record both temperature and relative humidity within the incubator during the course of each experiment. These data will ensure adequate conditions were maintained, and may explain deviations from expected results during changes in incubator conditions as a result of mechanical problems or changes in ambient conditions. See the BEEBOOK chapter on maintaining workers in cages (Williams et al., 2013) for more details.

\subsubsection{Inoculation methods 2.2.4.1. Spore source}

As with other parasites (Ferguson and Read, 2002), including N. bombi in bumble bees (Bombus spp.) (Tay et al., 2005) and bacterial diseases in honey bees (Genersh et al., 2005; Charriere et al, 2011), it is possible that genetic variants detected in both $N$. apis and N. ceranae (Williams et al., 2008; Chaimanee et al., 2010; Sagastume et al., 2011) may at least partially explain differences in host susceptibility and parasite virulence. Future studies should seek to identify genes responsible for Nosema epidemics (Chen and Huang, 2010). Based on differences in reported pathology of Nosema species around the world, researchers should state the region and country spores originated from. It is recommended that spores be sourced from multiple colonies.

When creating inoculums, it is important to use fresh spores because their viability is lost over time when spore suspensions are stored. In particular, this is true for $N$. ceranae isolates, which rapidly lose viability in the refrigerator and almost completely lose infection capacity after freezing of spores (Fenoy et al., 2009; Fries, 2010). See section 2.2.5. for viability test procedures. Group feeding of caged bees using crushed bees infected with the respective Nosema spp. in sugar solution is a good way to propagate spores for experiments (see sections 2.2.4.4. and 2.2.4.5. for details on individual and group feeding, respectively). After 10-12 days, spore-inoculated bees from cages maintained in appropriate conditions (section 2.2.3.4) can be extracted and the ventriculi used for preparations of spore suspensions according to methods described previously (section 2.2 .1 and 2.2.4.2). Molecular assays previously described (section 2.2.2.3) should be employed to ensure the proper species of spore is used for inoculations because mixed infections occur, even in naturally-infected individual 
bees (Burgher-MacLellan et al., 2010). Prepared spore suspensions can be used the next day when kept in sugar solution in the refrigerator (section 2.2.4.2.3)

\subsubsection{Spore suspension}

A suspension of spores obtained as described previously (e.g. 1 infected bee ventriculus in $1 \mathrm{ml}$ water; section 2.2.1.) can be filtered using sterile $74 \mu \mathrm{m}$ sized mesh to remove large pieces of host materials. After filtration, 1-5 mM pH 9.0-buffered ammonium chloride $\left(\mathrm{NH}_{4} \mathrm{Cl}\right)$ can be added to the filtrate to inhibit spore germination.

However, sometimes a high purity of spores is needed. Purification can remove unwanted host tissues and microbial contaminants that may confound experimental data, and can also facilitate accurate microscopic counting

\subsection{Purification}

The purpose of purifying a spore suspension is to remove unwanted host tissues and microbial contaminants that may confound experimental data. A high purity of spores can facilitate accurate microscopic counting and is an important quality assurance parameter in pathological studies. A number of purification methods describe below give high purity preparations, and the choice of purification method depends upon the specific requirements and applications of spore suspension. For in vivo feeding assays, it is sufficient to purify spores using filtration and centrifugation techniques. Alternatively, methods of triangulation or density gradient purification, in addition to initial filtration, are recommended for experiments that require a very high level of spore purity. Note that amount of water added to resuspend the pellet will affect the spore concentration and the final concentration of the inoculum must therefore be checked using a haemocytometer (see section 2.2.1.1. and the BEEBOOK paper on miscellaneous methods (Human et al., 2013).

\subsection{Centrifugation}

1. Centrifuge spore suspension at $5,000 \mathrm{G}$ for five minutes to produce a pellet of spores.

2. Discard supernatant containing tissue debris that is lighter than spores.

3. Resuspend the pelleted spores in distilled water by vortexing for five seconds.

Repeat the centrifugation 2-3 times to wash spores and to create a Nosema spore suspension with over $85 \%$ purity level.

\subsection{Triangulation}

1. Centrifuge spore suspension at $300 \mathrm{G}$ for five minutes to form a spore pellet which contains two strata, the upper supernatant fluid and the lower stationary phase containing most of spores.

2. Transfer supernatant fluid to another tube using a pipette, and resuspend lower stationary phase using sterile water.
3. Centrifuge supernatant for five minutes at $300 \mathrm{G}$ to pellet the spores, and again transfer supernatant fluid to another tube and resuspend the lower stationary phase.

4. Repeat procedure three times.

5. Combine resuspended lower strata created from each centrifugation to yield a spore suspension with a purity greater than $99 \%$ (Cole, 1970).

\subsection{Density gradient}

The most commonly used density gradient substrates used for microsporidian spore purification are sucrose, sodium chloride, cesium chloride, and two silica colloids: Ludox HS40 and Percoll. The density gradient can be continuous or discontinuous (i.e. stratified), heaviest at the bottom and lightest at the top, thus allowing purified particles to be located at specific regions of the density gradient. Among all density gradient media, Percoll is frequently used for Nosema spore purification because it offers many advantages, including: 1. Ease of preparation; 2. Low viscosity, permitting rapid sedimentation at low speed centrifugation; 3. Low osmolarity and no toxicity; 4. Excellent stability under any autoclaving sterilization conditions (Fig. 6).

Purification procedure with Percoll substrate

1. Gently overlay the Nosema spore suspension on a discontinuous Percoll (Sigma-Aldrich; St. Louis, USA) gradient consisting of $10 \mathrm{ml}$ each of 25, 50, 75, and 95\% Percoll solution from top to bottom, respectively.

2. Centrifuge the column at $10,000 \mathrm{G}$ for 20 minutes at $4^{\circ} \mathrm{C}$.

3. Discard the supernatant.

4. Re-suspend the pellet in sterile water.

5. Repeat the process 3 times.

6. Overlay the spore suspension on $20 \mathrm{ml} 100 \%$ Percoll solution.

7. Centrifuging the column at $3,000 \mathrm{G}$ for $2-3$ minutes to pellet the lighter cellular debris and leave the spores on the top of Percoll solution.

8. Dilute the $100 \%$ Percoll solution by adding the equal amount of water and pellet the spores by centrifugation at $10,000 \mathrm{G}$ for 15 minutes.

9. Re-suspend the spore pellet in $2-5 \mathrm{ml}$ sterile water to produce a spore suspension with a purity of greater than $99 \%$ (Chen et al., 2009).

\subsection{Spore suspension concentration}

Dilution of the purified spore suspension to the desired concentration can be performed using the formula: $C_{1} V_{1}=C_{2} V_{2}$ where: $C_{1}=$ initial concentration; $V_{1}=$ initial volume; $C_{2}=$ final concentration; $V_{2}=$ final volume.

For example, if you want to feed 10,000 Nosema spores in $10 \mu \mathrm{l}$ $50 \%$ (weight/volume) sucrose solution, you must, as determined by proportions, create a final spore concentration of $1,000,000$ spores / ml 


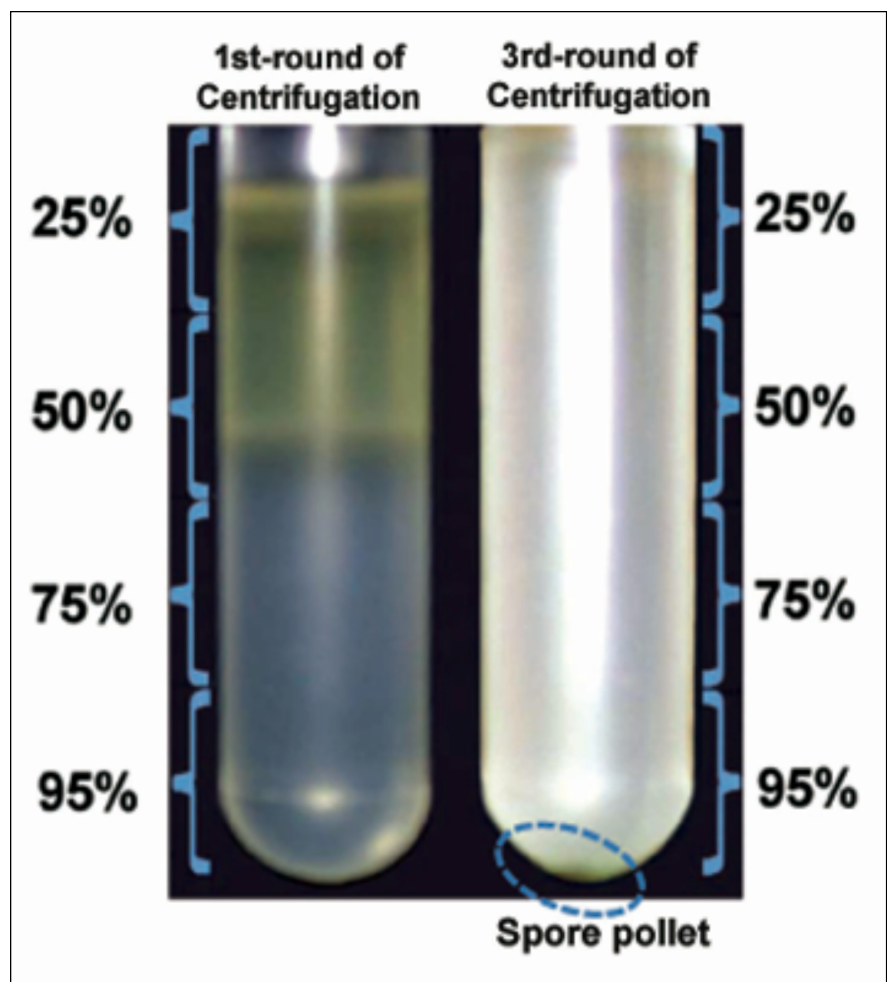

Fig. 6. The Percoll gradient will be constructed by layering $95 \%, 75 \%$, $50 \%$ and $25 \%$ Percoll solution from bottom to top in a $50 \mathrm{ml}$ ultracentrifuge tube. The spore suspension will be overlayed onto the gradient and centrifuged. After centrifugation, the supernatant will be removed and the spore pellet will be suspended in sterile water. After two or three times purification on Percoll gradient, the resulting pellet will contain very pure spores.

of $50 \%(\mathrm{w} / \mathrm{v})$ sucrose solution. To create $10 \mathrm{ml}$ of this final spore suspension in $50 \%$ sucrose solution when your initial spore suspension is: Example 1. 10,000,000 spores/ml water, then $1 \mathrm{ml}$ of initial spore suspension must be added to $9 \mathrm{ml} 55.6 \%$ (w/v) sucrose solution. See below for specific details:

Calculating initial volume of spore-water suspension needed

1. $C_{1} V_{1}=C_{2} V_{2}$

2. $\mathrm{V}_{1}=\mathrm{C}_{2} \mathrm{~V}_{2} / \mathrm{C}_{1}$

3. $V_{1}=1,000,000$ spores per $\mathrm{ml} \times 10 \mathrm{ml} / 10,000,000$ spores per $\mathrm{ml}$

4. $\mathrm{V}_{1}=1 \mathrm{ml}$

Calculating initial concentration of spore-free sucrose solution needed*

1. $C_{1} V_{1}=C_{2} V_{2}$

2. $\mathrm{C}_{1}=\mathrm{C}_{2} \mathrm{~V}_{2} / \mathrm{V}_{1}$

3. $C_{1}=50 \mathrm{~g}$ sucrose per $100 \mathrm{ml}$ water $X 10 \mathrm{ml}$ final sucrose solution / 9 initial sucrose solution

4. $55.56 \mathrm{~g}$ sucrose per $100 \mathrm{ml}$ water

*An initial concentration of spore-free sucrose solution of $50 \%$ is generally adequate when a low volume of spore suspension is added to create a final spore suspension in approximately $50 \%$ sucrose solution.

Example 2. $12,456,000 \mathrm{spores} / \mathrm{ml}$ water, then $0.8 \mathrm{ml}$ of initial spore suspension must be added to $9.2 \mathrm{ml} 54.3 \%(\mathrm{w} / \mathrm{v})$ sucrose solution.

Control suspensions to infected control bees should be created using uninfected individuals from the same colonies the spores were sourced from.

\subsection{Storage of stock suspension}

It should be emphasised that for infection experiments, newly made up spore suspensions should be used, prepared the same day or the day before the experiment and kept in the refrigerator. For $N$. apis, storage of spores for later preparations of new suspensions can be made by freezing adult infected bees or already prepared spore suspensions. For $N$. ceranae the situation is drastically different since the spores rapidly loose viability if frozen (Fenoy et al., 2009; Fries, 2010). A protocol needs to be developed whereby infective spores of $N$. ceranae can be reliably stored over longer periods without serious loss of viability.

\subsubsection{Handling of bees}

Bee caste, activity level, and personal comfort level will dictate what devices are used to manipulate bees. Most importantly, bees should not be crushed, so particular attention must be placed on ensuring sensitive and more fragile parts of the bee such as the abdomen, antennae, eyes, and mouthparts, are not disturbed or damaged. A honey bee that is damaged or has stung should be replaced.

In most cases, use of anaesthesia to handle honey bees is not required, and generally not recommended because of the difficulty of ensuring a consistent dosage is given to bees and because of possible effects on the behaviour, physiology, and development of insects (Czekonska, 2007; Ribbands, 1950; Rueppell et al., 2010). If anaesthesia is used, a consistent dosage should be provided to all experimental bees. Further details on handling and anaesthetising bees are provided in the BEEBOOK chapter on miscellaneous methods Human et al. (2013).

\subsubsection{Individual feeding}

Many Nosema laboratory experiments individually feed bees with an inoculum to ensure that bees are exposed to a known quantity of spores (e.g. Higes et al., 2007; Paxton et al., 2007; Maistrello et al., 2008; Forsgren and Fries, 2010). The volume of the inoculum can be 5 to $10 \mathrm{ml}$, amounts that are readily consumed by bees. Individual feeding of spores produces significantly lower variation in response infection level compared to group feeding of spores (Furgala and Maunder, 1961) and should be preferred for most experimental purposes until further investigations comparing group versus individually 
fed honey bees occurs. As with other laboratory procedures concerning Nosema, it is important to minimize chances of contamination by setting up sterile feeding stations unique to each treatment group. To individually inoculate honey bees with Nosema spores, refer to the BEEBOOK chapter on maintaining bees in vitro (Williams et al., 2013).

Specifically for Nosema studies, experimental bees should be starved in hoarding cages for two to four hours by removing all feeding devices to ensure that the entire inoculum is ingested quickly (e.g. Fries et al., 1992; Malone and Stefanovic, 1999; Higes et al., 2007; Maistrello et al., 2008). Bees destined for each treatment group should be maintained in separate hoarding cages to avoid the possibility of contamination during the removal of individuals for feeding. Because feeding can require considerable time depending on the number of bees to be inoculated and the number of persons available to feed spores, it may be necessary to house bees for each treatment group in multiple cages that can be starved in different time blocks to ensure that all individuals are without food for a similar period of time. Pre-trials will determine how much time is required for feeding, but generally it should take one to two minutes per bee. Additionally, and depending on the time required to feed all experimental bees, it may be prudent to rotate feeding amongst treatment groups so that, for example, not all bees from one treatment group are fed in the morning whereas bees from a second treatment group are fed in the afternoon. See previously discussed subsections within section 2.2.4., as well as section 2.2.7., for creating and choosing specific spore suspensions.

Once inoculated, bees can be placed into a $1.5 \mathrm{ml}$ microcentrifuge tube with a breathing hole at the end in suitable growth chamber conditions in detail below for 20 to 30 minutes to ensure that spores are not transferred among bees (see Williams et al., 2012) (Kellner and Jacobs, 1978; Verbeke et al., 1984). Afterwards, the bee can be placed in an appropriate treatment hoarding cage. The provided description can be applied to inoculating all castes. However, drones and queens can be transferred to appropriate treatment cages immediately after feeding because they are only recipients during trophallaxis (Crailsheim, 1998). Future studies should determine whether this is required as some debate exists regarding the frequency that newly emerged bees in cages engage in trophallaxis (Crailsheim, 1998).

\subsubsection{Group feeding}

In contrast to inoculating individual bees with Nosema spores as described above, inoculation can also occur by providing a group of caged bees with a spore suspension in one or more common feeding devices that may be fed on ad libitum. This method allows for individuals to be inoculated relatively quickly, and without the logistical and time constraints associated with individual feeding. Although not well studied, the primary disadvantage of group feeding of Nosema spores is the greater variance of Nosema intensity among caged individuals because of unequal distribution of the inoculum among individuals over time (Furgala and Maunder, 1961). Preliminary studies suggest group feeding is as effective at infecting caged bees as individual inoculation (Tanner et al., 2012). Greater cage replicates per treatment group may be required if group feeding of inoculum is used. Group inoculation of a spore suspension containing 10,000 and 33,300 spores per bee is sufficient to infect caged individuals (Webster, 1994; Pettis et al., 2012).

Further details on group feeding are provided in the BEEBOOK chapter on maintaining bees in cages (Williams et al., 2013). For Nosema, for example, to mass inoculate 100 honey bees with approximately 10,000 Nosema spores per bee:

1. Provide $1,000,000$ spores in $4 \mathrm{ml} 50 \%(\mathrm{w} / \mathrm{v})$ sucrose solution to guarantee that the entire volume will be consumed within approximately 24 hours.

This short time period will ensure a similar initial inoculation period for all individuals, and help prevent bacterial degradation of unconsumed spores from occurring.

2. Top up the feeder with $50 \%(w / v)$ sucrose solution when the inoculation solution is close to empty so that the caged honey bees do not go without food.

To ensure all spores are ingested, small volumes can be regularly added throughout the day until one is confident that most spores have been consumed.

When cultivating Nosema spores, live bees can be killed 10 to 14 days post-inoculation, approximately when a full $N$. apis infection is reached (Fries, 1988), using methods described by Human et al. (2013) in the $B E E B O O K$.

\subsubsection{Viability control of Nosema spores}

The viability of spores to be tested is rarely checked, although it is a crucial point to ensure the reliability and reproducibility of the results. In particular regarding $N$. ceranae, it can be considered as a key point because of the high sensibility to cold temperatures of $N$. ceranae, spores (Forsgren and Fries, 2010). N. apis spores also loose infectivity after freezing, but in a matter of years (Bailey, 1972) rather than a week as shown for $N$. ceranae (Fries, 2010).

Spore viability can be tested using three methods: colouration and infectivity tests (in vivo and in vitro). The advantage of colouration is that suspensions can be checked before use, in vivo tests are useful for confirmation of spore viability used for infection experiments.

\subsubsection{Colouration test for spore viability}

1. Add $50 \mathrm{ml}$ of spores in $\mathrm{H}_{2} \mathrm{O}$ at a concentration of $5 \times 105$ spores / $\mathrm{ml}$ to $1 \mathrm{mM}$ of Sytox green (Molecular Probes, Inc.).

2. Incubate for 20 minutes at room temperature.

3. Centrifuge for 3 minutes at $1600 \mathrm{xg}$ and discard the supernatant.

4. Homogenize the pellet 1.5 .

5. in $\mathrm{H}_{2} \mathrm{O}$ and centrifuge for 3 minutes at $1600 \times \mathrm{g}$. 
6. Discard the supernatant.

7. Add $100 \mathrm{ml} \mathrm{4}$,6-diamidino-2-phenylindole (DAPI) at $2 \mathrm{mg} / \mathrm{ml}$.

8. Incubate for 30 minutes in room temperature.

9. Centrifuge for 3 minutes at $1600 \times \mathrm{g}$ and discard the supernatant.

10. Homogenize the pellet in $\mathrm{H}_{2} \mathrm{O}$ and centrifuge for 3 minutes at $1600 \mathrm{xg}$ and discard the supernatant.

11. Add $50 \mathrm{ml} \mathrm{H}_{2} \mathrm{O}$ and apply aliquots if $15 \mathrm{ml}$ onto glass slides.

12. Allow to dry in room temperature and view under oil in a fluorescent microscope.

Dead spores are identified as yellow-green ovals through the 470- to 490-nm excitation wavelength filter, and living spores are coloured with turquoise ovals through the 395- to 415-nm excitation

wavelength filter. To differentiate extruded spores not visible by either Sytox green or DAPI staining, white-light microscopy, where extruded polar filaments can be seen (Fenoy et al., 2009). The colouration test for viability has not yet been evaluated with the ultimate test - in vivo tests in live bees.

\subsubsection{In vivo test for spore viability}

Experimentally, the viability of $N$. apis spores can be assessed by feeding suspensions with different spore concentrations to groups of newly emerged adult honey bees (see section 2.2.7.1). Honey bees exposed to spores can be collected 10 days post infection when the infection appears to be almost fully developed for both Nosema spp. (Higes et al., 2007; Martin-Hernandez et al., 2011; Forsgren and Fries, 2010) and the ventriculus examined for the presence of spores. If spores are seen in the light microscope, the bee is recorded as infected (Malone et al., 2001) and the viability of the spores in the suspension used can be calculated based on the $\mathrm{ID}_{50}$ and the $\mathrm{ID}_{100}$ obtained (see section 2.2.7.1).

\subsubsection{In vitro test for spore viability}

In vitro germination of spores of both Nosema spp. can also be triggered by a procedure that mimics the natural conditions for the germination of environmental spores. Since the germination is the first step in the infection process, this test gives data on spore infectivity ability (Gisder et al. 2010b) but the in vitro test for spore viability has not yet been evaluated with the ultimate test - in vivo tests in live bees. See section 2.2.6. for details on in vitro rearing of Nosema.

\subsubsection{In vitro rearing of Nosema spp.: cell culture systems}

Cell and tissue cultures are indispensable for the propagation and study of obligate intracellular pathogens like viruses and microsporidia. Bee pathogens comprise viruses and microsporidia as obligate intracellular parasites. However, studies on cellular and molecular aspects of pathogen-host interactions of these pathogens and their target cells have been hampered in the past by the complete lack of permanent bee cell lines. Recently, protocols for the prolonged although limited maintenance of primary honey bee cells have been described (Bergem et al., 2006; Hunter, 2010), but these cells have not been used for infection experiments. Several hundreds of non-honey bee insect cell lines are commercially available (Lynn, 2007; van Oers and Lynn, 2010) and have been proven to be valuable tools for elucidating attachment, entry, and replication of several intracellular insect pathogens and for analysing cellular reactions towards infection (Smagghe et al., 2009; van Oers and Lynn, 2010). However, these cell lines were considered unsuitable for the study of bee pathogens due to the assumed host specificity of bee pathogenic viruses and microsporidia. We here describe both, the infection of primary ventricular cells established from honey bee pupae as well as the infection of commercially available insect cell lines established from several lepidoptera with $N$. ceranae and $N$. apis. General techniques for cell cultures are described by Genersch et al. (2013) in the $B E E B O O K$

\subsubsection{Infection of primary honey bee ventricular cells}

1. Isolate pupal gut cells from 10 days old pupae as described in detail in the $B E E B O O K$ paper on cell culture techniques (Genersch et al., 2013).

2. Transfer approximately $5 \mathrm{E}+7$ Nosema spp. spores in $\mathrm{AE}-$ buffer (Qiagen) into chamber slides ( 2 well glass slide, VWR).

3. Air dry for 3 hours at room temperature.

4. Initialize spore-germination with $50 \mu \mathrm{l} 0.1 \mathrm{M}$ Sucrose in PBSbuffer (BDH, Laboratory Supplies).

5. Immediately resuspend $500 \mu \mathrm{l}$ primary cell suspension in fresh L15 medium ( $1.49 \%$ L-15, 0.4\% Glucose, 0.25\% Fructose, $0.33 \%$ Prolin, $3 \%$ Sucrose, all w/v, pH 7.2; for a recipe see Table 2) with the germinating spores.

6. Incubate the spore-cell suspension at $33^{\circ} \mathrm{C}$ for $20 \mathrm{~min}$.

7. Add $1 \mathrm{ml}$ of fresh and pre-warmed $\left(37^{\circ} \mathrm{C}\right) \mathrm{BM} 3$ medium ( $\mathrm{L} 15$ medium $+0.075 \%$ Pipes, $3 \%$ inactivated FCS, $1.2 \%$ Yeastolate, $10 \%$ antimycotic/antibiotic solution from SigmaAldrich, pH 6.7; for a recipe see Table 2).

8. Long time incubation is performed in a cooling incubator (Thermo Fisher) at $33^{\circ} \mathrm{C}$ for 144 hours.

9. Remove the supernatant by aspiration.

10. Fix cells with $500 \mu$ of $4 \%$ formalin solution (Roth) for 24 hours.

11. Identify infected cells by microscopic analysis (Figs 7A \& B).

Although the infection of primary pupal cells can be achieved, this approach is time consuming, does not easily lead to reproducible results, and is accompanied by the problem of seasonal dependency because sufficient numbers of pupae are only available during the brood rearing period. 
Table 2. Recipes for media used for infection of cultured primary honey bee ventricular cells with Nosema spp.

\begin{tabular}{|l|l|}
\hline BM 3 medium pH 6.7 & $\begin{array}{l}1000 \mathrm{ml} \text { L } 15 \text { medium + } 0.75 \mathrm{~g} \text { Pipes, } 30 \\
\text { ml FCS (inactivated), } 12 \mathrm{~g} \text { Yeastolate }\end{array}$ \\
\hline L 15 medium pH 7.2 & $\begin{array}{l}14.9 \mathrm{~g} \mathrm{~L}-15 \text { powder, } 4.0 \mathrm{~g} \text { glucose, } 2.5 \mathrm{~g} \\
\text { fructose, } \\
3.3 \mathrm{~g} \text { prolin, } 30 \mathrm{~g} \text { sucrose, ad } 1000 \mathrm{ml} \\
\text { bidest }\end{array}$ \\
\hline
\end{tabular}

\subsubsection{Infection of heterologous lepidopteran cell lines}

Most of the commercially available, permanent insect cell lines are derived from Lepidoptera. Several lepidopteran cell lines are described to support propagation of homologous microsporidia (where the source species of the cell line is the original host), as well as microsporidia originally infecting other hosts (Jaronski, 1984).

Likewise, several lepidopteran cell lines have proved to be susceptible to $N$. apis and $N$. ceranae infection. Susceptibility could recently be demonstrated for the following cell lines (Gisder et al., 2010b): MB-L2 (Mamestra brassicae), Sf-158 and Sf-21 (Spodoptera frugiperda), SPC-BM-36 (Bombyx mori), and IPL-LD-65Y (Lymantria dispar), and BTI-Tn-5B1-4 (Trichoplusia ni) which can all be obtained through national cell culture collections together with protocols how to maintain and passage the cell lines. It is recommended to maintain the cell lines for routine culture in $75 \mathrm{~cm}^{2}$ cell culture flasks (e.g. Roth) in a cooling incubator (e.g. Thermo Fisher) at $27^{\circ} \mathrm{C}$, and supply them with their individual medium composition (Table 3 ).

Approximately $2 \mathrm{E}+05$ cells per $\mathrm{ml}$ should be used to establish the next passage (Table 3 ).

For infection of these insect cell lines with germinating Nosema spp. spores (after Gisder et al., 2010b):

1. Prepare a pre-culture

2. Incubate the cells to their exponential growth phase.

3. Harvest the cells growing in exponential phase
Table 3. Maintained insect cell lines which can be infected with Nosema spp. FCS = fetal calf serum; w/o = without.

\begin{tabular}{|l|c|c|c|c|}
\hline cell line & $\begin{array}{c}\text { cell } \\
\text { growth }\end{array}$ & Medium & FCS & $\begin{array}{c}\text { time of } \\
\text { passage }\end{array}$ \\
\hline MB-L2 & $\begin{array}{c}\text { mostly } \\
\text { adherent }\end{array}$ & Insect-Xpress (Lonza) & w/o & every 5 days \\
\hline Sf-158 & adherent & Insect-Xpress (Lonza) & $5 \%$ & every 6 days \\
\hline Sf-21 & adherent & Insect-Xpress (Lonza) & $5 \%$ & every 6 days \\
\hline SPC-BM-36 & $\begin{array}{c}\text { mostly } \\
\text { adherent }\end{array}$ & TC-100 (Invitrogen) & $12 \%$ & every 7 days \\
\hline IPL-LD-65Y & suspension & TC-100 (Invitrogen) & $11 \%$ & every 7 days \\
\hline BTI-Tn-5B1-4 & adherent & Sf-900 II (Invitrogen) & w/o & every 5 days \\
\hline
\end{tabular}

4. Centrifuge at $210 x g$ for $5 \mathrm{~min}$. (Eppendorf $5810 \mathrm{R}$, rotor F34-6-38).

5. Remove medium by aspiration.

6. Wash the cell pellet twice with $1 \mathrm{ml}$ of freshly prepared $0.1 \mathrm{M}$ sucrose in PBS-buffer.

7. Dilute the cells to a final concentration of $2 \mathrm{E}+06$ cells per $\mathrm{ml}$ in $0.1 \mathrm{M}$ sucrose solution.

8. Transfer approximately $5 \mathrm{E}+07$ freshly prepared spores (see above), diluted in AE-buffer (Qiagen), were into a chamber slide (VWR, 4 chambers each slide) for infection.

9. Air dry for 3 hours at room temperature.

10. Initialize infection by adding $100 \mu \mathrm{l} 0.1 \mathrm{M}$ sucrose in PBS buffer to the dried spores, so that spore germination is triggered.

11. Immediately add $50 \mu \mathrm{l}$ of cell suspension $(2.5 \mathrm{E}+05$ cells) to the germinating spores.

12. Resuspend the spore-cell suspension ( $150 \mu \mathrm{l})$ thoroughly.

13. Incubate at room temperature for 5 minutes.

14. Add $350 \mu \mathrm{l}$ medium with $250 \mu \mathrm{g} \mathrm{ml}^{-1}$ penicillin/streptomycin (Roth) and $125 \mu$ l antimycotic/antibiotic solution (SigmaAldrich) to the spore-cell suspension to a final volume of $500 \mu$ l.

15. Incubate the cells at $27^{\circ} \mathrm{C}$ up to 10 days.

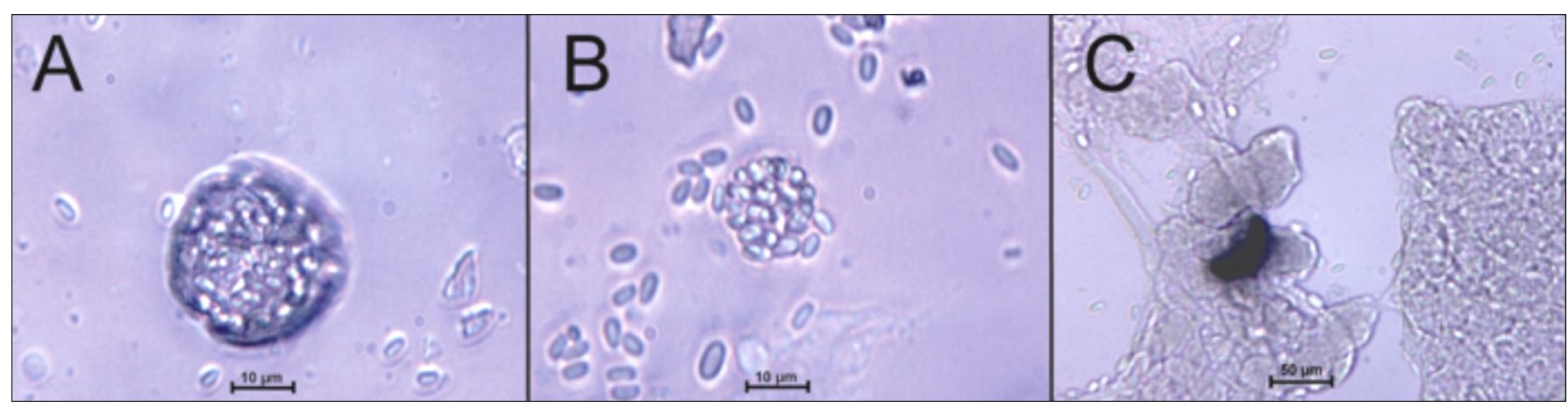

Fig. 7 A-C. Infection assay with Nosema spp. and primary pupal gut cells: A. infected primary ventricular cell; B. dissolving primary cell releasing new spores; $\mathrm{C}$. in situ-hybridization (ISH) of infected ventricular cells, infected cells are stained blue. Specific hybridization was performed with $16 \mathrm{~S}$ rRNA (SSU) probes coupled with digoxigenin and colour reaction to detect hybridized probes. Bars $(A, B)$ represent $10 \mu \mathrm{m}$ and bar in $\mathrm{C}$ represents $50 \mu \mathrm{m}$. 


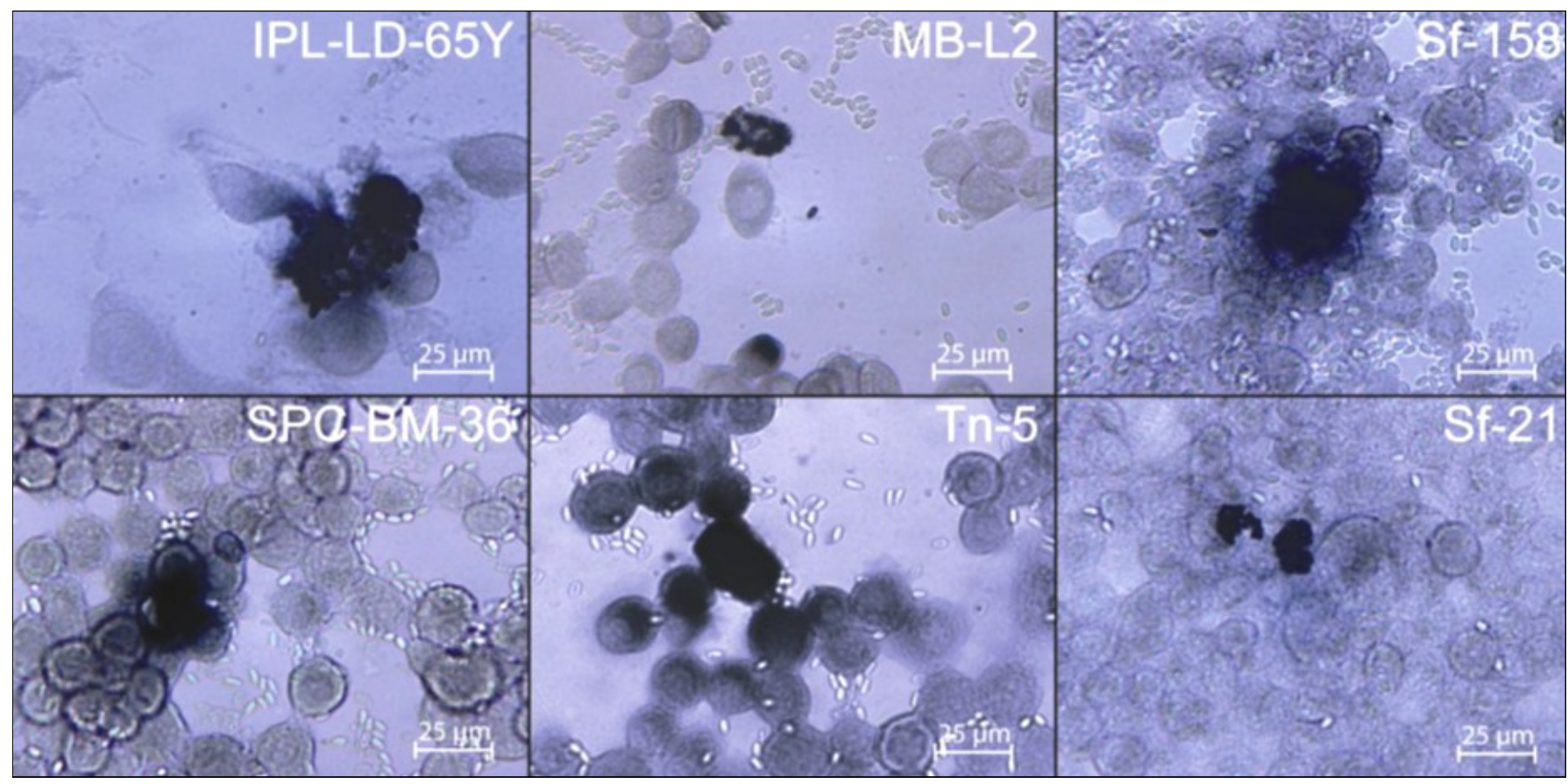

Fig. 8. In situ-hybridization (ISH) of Nosema spp. infected lepidopteran cell lines 72 hours post infection. Infected cells are stained dark blue. Specific hybridization was performed with 16S rRNA (SSU) probes coupled with digoxigenin and subsequent colour reaction to detect hybridized probes.

For in situ-hybridization (ISH) or fluorescence in situ-hybridization (FISH) medium was aspirated and cells were fixed on glass slides with $4 \%$ formalin (e.g. Roth) up to 24 hours. (Fig. 7c) ISH or FISH were performed according to recently published protocols (Gisder et al., 2010b; Yue et al., 2007, see also the BEEBOOK paper on molecular methods (Evans et al., 2013)).

Six lepidopteran cell lines could be infected successfully (Fig. 8) as demonstrated by in situ-hybridization performed 72 hours post infection. For a detailed analysis of the life cycle of Nosema spp. in infected cells, IPL-LD-65Y cells were chosen and analysed by fluorescence in situ-hybridization (FISH, see the BEEBOOK paper on molecular methods (Evans et al., 2013)). Although these newly developed cell culture models are valuable tools for studying pathogen-host interactions on cellular and molecular level (Troemel, 2011), the protocol does not yet allow the continuous propagation of Nosema spp. in cell culture and, hence, is not yet suitable to replace infection of bees for the production of spore suspensions.

\subsubsection{Experiment type}

Prior to any experiment with induced Nosema spp. infections, the infection level in the source colonies for bees to be used should be assessed prior to experimentation (see section 2.2.1). This is advisable also when bees for infection experiments are hatched in incubators.

\subsubsection{Determination of infectious dose}

The infectious dose (the dose that infects half of inoculated bees $\left(\mathrm{ID}_{50}\right)$ or $100 \%\left(\mathrm{ID}_{100}\right)$ can be calculated relatively precisely when experimental bees are individually inoculated as described in section 2.2.4.4. and incubated in hoarding cages. The proportion of infected bees given different doses is then examined after 7-10 days. Usually, inoculums are prepared from a stock suspension of spores that is subsequently diluted (section 2.2.4.2.2). The final quantity of spores given to bees is therefore theoretical (= calculated). Under some circumstances and when the protocol is adapted to the goal of the study, the technique of group feeding can be used and gives reliable results (Pettis et al., 2012; Tanner et al. (2012)). When the bees are mass fed, the quantity of spores given to each bee is an average count calculated from the overall quantity distributed to a given number of bees, but it should be noted, that group feeding is likely to yield an uneven distribution of spore dose among bees (section 2.2.4.5.). Similar to pesticide studies, where the lethal dose to $50 \%$ $\left(L D_{50}\right)$ or $100 \%\left(L D_{100}\right)$ of tested insects are used to describe toxicity, the infectious dose can be described as the dose that produces infection in $50 \%\left(\mathrm{ID}_{50}\right)$ or $100 \%$ of exposed insects $\left(\mathrm{ID}_{100}\right)$. For $N$. apis, $\mathrm{ID}_{50}$ has been determined to roughly 100 spores per bee (Fries, 1988), with 10,000 spores producing infection in all exposed honey bees (Czekonska, 2007; Fries, 1988). Recently, similar experiments were performed that compared $N$. apis and $N$. ceranae. Results revealed a slightly lower $\mathrm{ID}_{50}$ for $N$. ceranae (Forsgren and Fries, 2010). It should 
be noted that little is known about possible variations in infectivity between parasite isolates and/or different levels of susceptibility between host strains and, thus, infectious dose experiments need to be repeated using different bees and different spore sources.

\subsection{Study of dose effects}

Although the doses of 10,000 and 33,000 spores per bee have been shown to produce infection in all exposed bees, it is common to use much higher doses, even an order of magnitude higher or more, to ensure infection (Alaux et al., 2010a; Alaux et al., 2010b, Paxton et al., 2007; Malone and Stefanovic, 1999; Higes et al., 2007; Porrini et al., 2010; Webster et al., 2004; Woyciechowski and Moron, 2009). Depending on the type of experiment, it is often best not to use higher spore doses than is necessary to produce infection in individual bees, because when high spore doses are used, non-germinated spores may be retrieved and counted as spores produced from infection.

Honey bee queens become infected by both $N$. apis and $N$. ceranae. As with workers, a range of different doses have been used to study effects of infection on queens individually fed, although again, more spores were provided than were required (Alaux et al. 2010c; Webster, 2008). Using individual feeding, queens and worker bees have become infected using similar spore doses (Webster et al., 2004), but the infectious doses for queens have never been established for either of the two microsporidian infections discussed.

\subsection{Effects of different infection doses}

It is necessary to test serial quantities of spores if the interest of the experiment is to investigate the effect of infection dose. In this case, for more precision, honey bees should always be individually fed the spore suspensions. The quantities of spores given to bees could increase by a factor of 10 (Forsgren and Fries, 2010; Malone et al., 2001), but other increments can also be used (Martin-Hernandez et al., 2011).

\subsubsection{Course of infection in individual bees}

The course of infection is checked in individual bees or in a group of tested bees. The time lap between spore counts has been highly variable between different authors and the goal of the experiment (Alaux et al., 2010a; Alaux et al., 2010b; Czekonska, 2007; Forsgren and Fries, 2010; Malone and Stefanovic, 1999; Paxton et al., 2007). Generally speaking, a greater sample size and increased frequency of sampling will allow for more confidence in the data. Since individual feeding of honey bees is time consuming, the interval between sampling and the number of bees investigated must, nevertheless, be limited. Because $N$. apis spores are not produced from new infections until at least 3 days post infection (Fries, 1988 ; Fries et al., 1996; Forsgren and Fries, 2010), with the first spores of $N$. ceranae produced slightly later (Forsgren and Fries, 2010), sampling should be initiated no earlier than 4 days post infection. With a 2 day time interval between sampling, a relatively detailed data set on spore development can be accomplished. Because of variations in spore development between different bees, the sample size should never be below 3-4 bees per cage and treatment, and for statistical reasons, the more bees used, the better (see the statistics section in the BEEBOOK paper on miscellaneous methods (Human et al., 2013)).

\subsubsection{Longevity of infected bees}

There is a surprising lack of data on the actual longevity of infected honey bees, probably because the mortality is rarely assessed per se. When the mortality takes place 10 to 14 days or more after the exposure to the spores, the researchers usually decide to sacrifice the tested honey bees. For $N$. ceranae, 100\% mortality of infected bees have been reported within this time frame (Higes et al., 2007; MartinHernandez, et al., 2011), but significantly lower mortality rates have also been observed (Dussaubat et al., 2010; Forsgren and Fries, 2010; Paxton et al., 2007; Porrini et al., 2010). There is a profound need for more mortality data from Nosema spp. infections, to better understand the impact from infection on colony viability. Possibly, cage experiments are less well suited for such tests because cage effects on longevity cannot be excluded, even if proper controls are used. An alternative would be to use marked bees, with and without infection, and introduce them to small functioning colonies and then study the rate at which such honey bees disappear compared to uninfected bees (see the section on statistics for survival analyses in the BEEBOOK paper on miscellaneous methods (Human et al., 2013)).

Only a few studies have investigated the longevity of queens when infected with $N$. apis. spores. Young infected queens that were allowed to lay eggs all died about 50 days after the onset of oviposition, with an average age when found dead or removed by the bees of about 25 days (Loskotova et al., 1980). The impact from infection on queen as well as colony performance also need further studies to assess the impact on colony performance from these infections.

\section{Future perspectives}

The Nosema spp. parasites in honey bees still remain largely enigmatic. The described field symptoms differ between the parasites (Fries et al., 2006), as do the seasonal prevalence (Higes et al., 2008a, b). These observations suggest that the main mode of transmission between bees could differ between $N$. apis and $N$. ceranae. Faecal deposition within bee hives is associated with $N$. apis infections, but this is not the case with $N$. ceranae (Fries et al., 2006). The main mode of parasite transmission for $N$. apis is believed to be a faecaloral route through soiled comb (Bailey, 1953). There is a need to elucidate the main mode of transmission for $N$. ceranae to understand more of the epidemiology of this parasite. There is also a profound 
lack of data on differences in susceptibility of both parasites among different honey bee strains. Using standardized laboratory infectivity tests, it is probably possible to find differences in susceptibility to infection, both within and between strains of bees. With such information, breeding for resistance can be undertaken and genetic markers for resistance could possibly be located for genetic marker aided selection for disease resistance. As with differences in resistance in the host, it is likely that different isolates of the parasites differ in infectivity as well as in virulence. Although such differences have never been documented, along with differences in host susceptibility, they could complicate interpretations of experiments and possibly explain some contradictory results published on parasite virulence.

Ring tests among laboratories would be very useful for the scientific community but remain to be organized and funded.

The use of cell culture for studying the Nosema parasites is still in its infancy. With further developments, where continuous propagation of Nosema spp. in cell cultures becomes possible, new insights into infection biology may be gained. Also, there is a need to develop a reliable method for the long term storage of infective $N$. ceranae spores.

Lastly, a further complication when studying the Nosema parasites in honey bees is the associated virus infections. Infection with $N$. apis is associated with three unrelated viral infections; black queen cell virus (BQCV), bee virus $Y$ (BVY) and filamentous virus (FV).

A combination of $N$. apis and BQCV is distinctly more harmful than either infection alone, infection with BVY adds to $N$. apis virulence, whereas no such influence is seen with FV infections (Bailey et al., 1983). Interestingly, N. ceranae infections have been shown to be negatively correlated with deformed wing virus (DWV) (Costa et al., 2011).

\section{Acknowledgements}

The 7th framework project BEE DOC and the Ricola foundation supported this work period.

\section{References}

ALAUX, C; BRUNET, J L; DUSSAUBAT, C; MONDET, F; TCHAMITCHAN S; COUSIN, M; BRILLARD, J; BALDY, A; BELZUNCES, L P; LE CONTE, Y (2010a) Interactions between Nosema microspores and a neonicotinoid weaken honey bees (Apis mellifera). Environmental Microbiology 12: 774-782. http://dx.doi.org/10.1111/j.1462-2920.2009.02123.x ALAUX, C; DUCLOZ, F; CRAUSER, D ; LE CONTE, Y (2010b) Diet effects on honey bee immunocompetence. Biology Letters 6(4): 562-565. http://dx.doi.org/10.1098/rsbl.2009.0986
ALAUX, C; FOLSCHWEILLER, M; MCDONNELL, C; BESLAY, D; COUSIN, M; DUSSAUBAT, C; BRUNET, J L; LE CONTE, Y (2010c) Pathological effects of the microsporidium Nosema ceranae on honey bee queen physiology (Apis mellifera). Journal of Invertebrate Pathology 106(3): 80-385. http://dx.doi.org/10.1016/j.jip.2010.12.005

ALLEN, M D (1959) Respiration rates of worker honey bees of different ages and at different temperatures. Journal of Experimental Biology 36(1): 92-101.

AMDAM, G V; AASE, A L T O; SEEHUUS, S-C; FONDRK, M K; NORBERG, K; HARFELDER, K (2005) Social reversal of immunsenescence in honey bee workers. Experimental Gerontology 40(12): 939-947. http://dx.doi.org/10.1016/j.exger.2005.08.004

AMDAM, G V; RUEPPELL, O; FONDRK, M K; PAGE, R E; NELSON, C M (2009). The nurse's load: early-life exposure to brood-rearing affects behaviour and lifespan in honey bees (Apis mellifera). Experimental Gerontology 44(6-7): 467-471. http://dx.doi.org/10.1016/j.exger.2009.02.013 ANTÚNEZ, K; MARTIN-HERNANDEZ, R; PRIETO, L; MEANA, A; ZUNINO P; HIGES M (2009) Immune suppression in the honey bee (Apis mellifera) following infection by Nosema ceranae (Microsporidia). Environmental Microbiology 11(9): 2284-2290. http://dx.doi.org/10.1111/j.1462-2920.2009.01953.x

BAILEY, L (1953) The transmission of nosema disease. Bee World 34: 171-172.

BAILEY, L (1955) The epidemiology and control of Nosema disease of the honey-bee. Annals of Applied Biology 43(1-2): 379-389.

BAILEY, L (1972) The preservation of infective microsporidan spores. Journal of Invertebrate Pathology 20(3): 252-254. http://dx.doi.org/10.1016/0022-2011(72)90152-8

BAILEY, L; BALL, B V; PERRY, J N (1983) Association of viruses with 2 protozoal pathogens of the honey bee. Annals of Applied Biology 103(1): 3-20. http://dx.doi.org/10.1111/j.1744-7348.1983.tb02735.x

BARKER, R J; LEHNER, Y (1978) Laboratory comparison of high fructose corn syrup, grape syrup, honey, and sucrose syrup as maintenance food for caged honey bees. Apidologie 9(2): 111-116. http://dx.doi.org/10.1051/apido:19780203

BERGEM, M; NORBERG, N; AAMODT, R A (2006) Long-term maintenance of in vitro cultured honey bee (Apis mellifera) embryonic cells. BMC Developmental Biology 6(Article 17). http://dx.doi.org/10.1186/1471-213X-6-17

BOURGOIS, A L; BEARMAN, L D; HOLLOWAY, B; RINDERER, T E (2012) External and internal detection of Nosema ceranae on honey bees using real-time PCR. Journal of Invertebrate Pathology 109(3): 323-325. http://dx.doi.org/10.1016/j.jip.2012.01.002 
BOURGEOIS, L A; RINDERER, T E; BEAMAN, L D; DANKA, R G (2010) Genetic detection and quantification of Nosema apis and $N$. ceranae in the honey bee. Journal of Invertebrate Pathology 103(1): 53-58. http://dx.doi.org/10.1016/j.jip.2009.10.009

BORCHERT, A (1928) Beiträge zur Kenntnis der Bienen Parasiten Nosema apis. Archive für Bienenkunde 9: 115-178.

BOTÍAS, C; MARTÍN-HERNÁNDEZ, R; BARRIOS, L; GARRIDO-BAILÓN, E; NANETTI, A; MEANA, A; HIGES, M (2012b) Nosema spp. parasitization decreases the effectiveness of acaricide strips (Apivar ${ }^{\circledR}$ ) in treating varroosis of honey bee (Apis mellifera iberiensis) colonies. Environmental Microbiology Reports 4(1): 57-65. http://dx.doi.org/10.1111/j.1758-2229.2011.00299.x.v

BOTÍAS, C; MARTÍN-HERNÁNDEZ, R; DIAS, J; GARCÍA-PALENCIA, P; MATABUENA, M; JUARRANZ, A; BARRIOS, L; MEANA, A; NANETTI, A; HIGES, M (2012a) The effect of induced queen replacement on Nosema spp. infection in honey bee (Apis mellifera iberiensis) colonies. Environmental Microbiology 14(4): 845-859. http://dx.doi.org/10.1111/j.1462-2920.2011.02647.x

BOTÍAS, C; MARTÍN-HERNÁNDEZ, R; GARRIDO-BAILÓN, E; GONZÁLEZ PORTO, A, MARTÍNEZ-SALVADOR, A, DE LA RÚA, P, MEANA, A; HIGES, M (2011) The growing prevalence of Nosema ceranae in honey bees in Spain, an emerging problem for the last decade. Research in Veterinary Sciences 93(1): 150-155. http://dx.doi.org/10.1016/j.rvsc.2011.08.002

BOURGOIS, A L; BEARMAN, L D; HOLLOWAY, B; RINDERER, T E (2012) External and internal detection of Nosema ceranae on honey bees using real-time PCR. Journal of Invertebrate Pathology 109(3): 323-325. http://dx.doi.org/10.1016/j.jip.2012.01.002

BOURGEOIS, L A; RINDERER, T E; BEAMAN, L D; DANKA, R G (2010) Genetic detection and quantification of Nosema apis and $N$. ceranae in the honey bee. Journal of Invertebrate Pathology 103(1): 53-58. http://dx.doi.org/10.1016/j.jip.2009.10.009

BRODSCHNEIDER, R; CRAILSHEIM, K (2010) Nutrition and health in honey bees. Apidologie 41(3): 278-294.

http://dx.doi.org/10.1051/apido/2010012

BÜCHLER, R; ANDONOV, S; BIENEFELD, K; COSTA, C; HATJINA, F; KEZIC, N; KRYGER, P; SPIVAK, M; UZUNOV, A; WILDE, J (2013) Standard methods for rearing and selection of Apis mellifera queens. In V Dietemann; J D Ellis; P Neumann (Eds) The COLOSS BEEBOOK, Volume I: standard methods for Apis mellifera research. Journal of Apicultural Research 52(1): http://dx.doi.org/10.3896/IBRA.1.52.1.07

BURGHER-MACLELLAN, K L; WILLIAMS, G R; SHUTLER, D; ROGERS, R E L; MACKENZIE, K (2010) Optimization of duplex real-time PCR with melting curve analysis for detection of microsporidian parasites Nosema apis and Nosema ceranae in Apis mellifera. Canadian Entomologist 142(3): 271-283. http://dx.doi.org/10.4039/n10-010
BURGES, H D; CANNING, E U; HULLS, I K (1974) Ultrastructure of Nosema oryzaephili and the taxonomic value of the polar filament. Journal of Invertebrate Pathology 23(2): 135-139. http://dx.doi.org/10.1016/0022-2011(74)90176-1

CANTWELL, G E (1970) Standard methods for counting nosema spores. American Bee Journal 110(6): 222-223.

CANTWELL, G E, SHIMANUKI, H (1969) Heat treatment as a means of eliminating nosema and increasing production. American Bee Journal 109(2): 52-54.

CARRECK, N L; ANDREE, M; BRENT, C S; COX-FOSTER, D; DADE, H A; ELLIS, J D; HATJINA, F; VANENGELSDORP, D (2013) Standard methods for Apis mellifera anatomy and dissection. In V Dietemann; J D Ellis; P Neumann (Eds) The COLOSS BEEBOOK, Volume I: standard methods for Apis mellifera research. Journal of Apicultural Research 52(4): http://dx.doi.org/10.3896/IBRA.1.52.4.03

CHAIMANEE, V; WARRIT, N; CHANTAWANNAKUL, P (2011) Infections of Nosema ceranae in four different honey bee species. Journal of Invertebrate Pathology 105(3): 207-210.

http://dx.doi.org/10.1016/j.jip.2011.05.012

CHARRIĖRE, J-D; KILCHENMANN, V; RÖTSCHI, A (2011) Virulence of different Melissococcus plutonius strains on larvae tested by an in vitro larval test; In Proceedings of the $42^{\text {nd }}$ International Apicultural Congress, Buenos Aires, Argentina. p 158.

CHEN, Y; EVANS, J D; MURPHY, C; GUTELL, R; ZUKER, M; GUNDENSEN-RINDAL, D; PETTIS, J S (2009) Morphological, molecular, and phylogenetic characterization of Nosema ceranae, a microsporidian parasite isolated from the European honey bee, Apis mellifera. Journal of Eukaryotic Microbiology 56(2): 142-147. http://dx.doi.org/10.1111/j.1550-7408.2008.00374.x

CHEN, Y; EVANS, J D; SMITH, I B; PETTIS, J S (2008) Nosema ceranae is a long-present and widespread microsporidian infection of the European honey bee (Apis mellifera) in the United States. Journal of Invertebrate Pathology 97(2): 186-188. http://dx.doi.org/10.1016/j.jip.2007.07.010

CHEN, Y P; HUANG, Z Y (2010) Nosema ceranae, a newly identified pathogen of Apis mellifera in the USA and Asia. Apidologie 41(3): 364-374. http://dx.doi.org/10.1051/apido/2010021

COBEY, S W; TARPY, D R ; WOYKE, J (2013) Standard methods for instrumental insemination of Apis mellifera queens. In V Dietemann; $J$ D Ellis; P Neumann (Eds) The COLOSS BEEBOOK, Volume I: standard methods for Apis mellifera research. Journal of Apicultural Research 52(4): http://dx.doi.org/10.3896/IBRA.1.52.4.09

COLE, R J (1970) Application of triangulation method to purification of Nosema spores from insect tissues. Journal of Invertebrate Pathology 15(2): 193-195. http://dx.doi.org/10.1016/0022-2011(70)90233-8 
COLTON, T (1974) Statistics in medicine. Little, Brown and Company; Boston, USA. $372 \mathrm{pp}$.

COSTA, C; TANNER, G; LODESANI, M; MAISTRELLO, L; NEUMANN, P (2011) Negative correlation between Nosema ceranae spore loads and deformed wing virus infection levels in adult honey bee workers. Journal of Invertebrate Pathology 108(3): 224-225. http://dx.doi.org/10.1016/j.jip.2011.08.012

CRAILSHEIM, K (1991) Interadult feeding of jelly in honey bee (Apis mellifera L) colonies. Journal of Comparative Physiology B 161(1): 55-60. http://dx.doi.org/10.1007/BF00258746

CRAILSHEIM, K (1998) Trophallactic interactions in the adult honey bee (Apis mellifera L.). Apidologie 29(1-2): 97-112. http://dx.doi.org/10.1051/apido:19980106

CURRIE, R W; PERNAL, S F; GUZMAN-NOVOA, E (2010) Honey bee colony losses in Canada. Journal of Apicultural Research 49(1): 104-106. http://dx.doi.org/10.3896/IBRA.1.49.1.18

CZEKONSKA, K (2007) Influence of carbon dioxide on Nosema apis infection of honey bees (Apis mellifera). Journal of Invertebrate Pathology 95(2): 84-86. http://dx.doi.org/10.1016/j.jip.2007.02.001

DADE, H A (2009) Anatomy and dissection of the honey bee (Revised edition). International Bee Research Association; Cardiff, UK. 196 pp. DE GRAAF, D C; ALIPPI, A M; ANTÚNEZ, K; ARONSTEIN, K A; BUDGE, G; DE KOKER, D; DE SMET, L; DINGMAN, D W; EVANS, J D; FOSTER, L J; FÜNFHAUS, A; GARCIA-GONZALEZ, E; GREGORC, A; HUMAN, H; MURRAY, K D; NGUYEN, B K; POPPINGA, L; SPIVAK, M; VANENGELSDORP, D; WILKINS, S; GENERSCH, E (2013) Standard methods for American foulbrood research. In $V$ Dietemann; J D Ellis; P Neumann (Eds) The COLOSS BEEBOOK, Volume II: standard methods for Apis mellifera pest and pathogen research. Journal of Apicultural Research 52(1): http://dx.doi.org/10.3896/IBRA.1.52.1.11

DELAPLANE, K S; VAN DER STEEN, J; GUZMAN, E (2013) Standard methods for estimating strength parameters of Apis mellifera colonies. In V Dietemann; J D Ellis; P Neumann (Eds) The COLOSS BEEBOOK, Volume I: standard methods for Apis mellifera research. Journal of Apicultural Research 52(1):

http://dx.doi.org/10.3896/IBRA.1.52.1.03

DE MIRANDA, J R; BAILEY, L; BALL, B V; BLANCHARD, P; BUDGE, G; CHEJANOVSKY, N; CHEN, Y-P; VAN DOOREMALEN, C; GAUTHIER, L; GENERSCH, E; DE GRAAF, D; KRAMER, M; RIBIÈRE, M; RYABOV, E; DE SMET, L VAN DER STEEN, J J M (2013) Standard methods for virus research in Apis mellifera. In V Dietemann; $J D$ Ellis; P Neumann (Eds) The COLOSS BEEBOOK, Volume II: standard methods for Apis mellifera pest and pathogen research. Journal of Apicultural Research 52(4): http://dx.doi.org/10.3896/IBRA.1.52.4.22
DIETEMANN, V; NAZZI, F; MARTIN, S J; ANDERSON, D; LOCKE, B; DELAPLANE, K S; WAUQUIEZ, Q; TANNAHILL, C; ZEGELMANN, B; ROSENKRANZ, P; ELLIS, J D (2013) Standard methods for varroa research. In V Dietemann; J D Ellis; $P$ Neumann (Eds) The COLOSS BEEBOOK, Volume II: standard methods for Apis mellifera pest and pathogen research. Journal of Apicultural Research 52(1): http://dx.doi.org/10.3896/IBRA.1.52.1.09

DOULL, K M (1965) The effects of time of day and method of sampling on the determination of nosema disease in bee hives. Journal of Invertebrate Pathology 7(1): 1-4. http://dx.doi.org/10.1016/0022-2011(65)90143-6

DOULL, K M, CELLIER, K M (1961) A survey of the incidence of Nosema disease (Nosema apis Zander) in honey bees in South Australia. Journal of Insect Pathology 3(3): 280-288.

DOULL, K M; ECKERT, J E (1962) A survey of the incidence of Nosema disease in California. Journal of Economic Entomology 55(3): 313-317. DUSSAUBAT, C; MAISONNASSE, A; ALAUX, C; TCHAMITCHAN, S; BRUNET, J L; PLETTNER, E; BELZUNCES, L P; LE CONTE, Y (2010) Nosema spp. Infection alters pheromone production in honey bees (Apis mellifera). Journal of Chemical Ecology 36(5): 522-525. http://dx.doi.org/10.1007/s10886-010-9786-2

EL-SHEMY, A A M; PICKARD, R S (1989) Nosema apis Zander infection levels in honey bees of known age. Journal of Apicultural Research 28(2): 101-106.

ERLER, S; LOMMATZSCH, S; LATTORFF, H (2012) Comparative analysis of detection limits and specificity of molecular diagnostic markers for three pathogens (Microsporidia, Nosema spp.) in the key pollinators Apis mellifera and Bombus terrestris. Parasitology Research 110(4): 1403-1410. http://dx.doi.org/10.1007/s00436-011-2640-9

EVANS, J D; SPIVAK, M (2010) Socialized medicine: individual and communal disease barriers in honey bees. Journal of Invertebrate Pathology 103(S): S62-S72.

http://dx.doi.org/10.1016/j.jip.2009.06.019

EVANS, J D; CHEN, Y P; CORNMAN, R S; DE LA RUA, P; FORET, S; FOSTER, L; GENERSCH, E; GISDER, S; JAROSCH, A; KUCHARSKI, R; LOPEZ, D; LUN, C M; MORITZ, R F A; MALESZKA, R; MUÑOZ, I; PINTO, M A; SCHWARZ, R S (2013) Standard methodologies for molecular research in Apis mellifera. In $V$ Dietemann; $J$ D Ellis; $P$ Neumann (Eds) The COLOSS BEEBOOK, Volume I: standard methods for Apis mellifera research. Journal of Apicultural Research 52(4): http://dx.doi.org/10.3896/IBRA.1.52.4.11 FARRAR, C L (1947) Nosema losses in package bees as related to queen supersedure and honey yields. Journal of Economic Entomology 40(3): 333-338. 
FENOY, S; RUEDA, C; HIGES, M; MARTÍN-HERNÁNDEZ, R; DEL AGUILA, C (2009) High-level resistance of Nosema ceranae, a parasite of the honey bee, to temperature and desiccation. Applied and Environmental Microbiology 75(21): 6886-6889. http://dx.doi.org/10.1128/AEM.01025-09

FERGUSON, H M; READ, A F (2002) Genetic and environmental determinants of malaria parasite virulence in mosquitoes. Proceedings of the Royal Society London B 269(1497): 12171224. http://dx.doi.org/10.1098/rspb.2002.2023

FLURI, P (1977) Juvenile hormone, vitellogenin and haemocyte composition in winter worker honey bees (Apis mellifera). Experientia 33(9): 1240-1241. http://dx.doi.org/10.1007/BF01922354 FORSGREN, E; FRIES, I (2010) Comparative virulence of Nosema ceranae and Nosema apis in individual European honey bees. Veterinary Parasitology 170(3-4): 212-217. http://dx.doi.org/10.1016/j.vetpar.2010.02.010

FRIES, I (1988) Infectivity and multiplication of Nosema apis Z. in the ventriculus of the honey bee. Apidologie 19(3): 319-328. http://dx.doi.org/10.1051/apido:19880310

FRIES, I (1989) Observations on the development and transmission of Nosema apis Z. in the ventriculus of the honey bee. Journal of Apicultural Research 28(2): 107-117.

FRIES I (1993) Nosema apis - a parasite in the honey bee colony. Bee World 74(1): 5-19.

FRIES, I (2010) Nosema ceranae in European honey bees (Apis mellifera). Journal of Invertebrate Pathology 103(S): S73-S79. http://dx.doi.org/10.1016/j.jip.2009.06.017

FRIES, I; EKBOHM, G; VILLUMSTAD, E (1984) Nosema apis, sampling techniques and honey yield. Journal of Apicultural Research 23(2): 102-105.

FRIES, I; FENG, F; SILVA, A; DA SLEMENDA, S B; PIENIAZEK, N J (1996) Nosema ceranae n. sp. (Microspora, Nosematidae), morphological and molecular characterization of a microsporidian parasite of the Asian honey bee Apis cerana (Hymenoptera, Apidae). European Journal of Protistology 32(3): 356-365.

FRIES, I; GRANADOS, R R; MORSE, R A (1992) Intracellular germination of spores of Nosema apis Z. Apidologie 23(1): 61-71. http://dx.doi.org/10.1051/apido:19920107

FRIES, I; MARTIN, R; MEANA, A; GARCIA-PALENCIA, P; HIGES, M (2006) Natural infections of Nosema ceranae in European honey bees. Journal of Apicultural Research 45(4): 230-233.

FURGALA, B; HYSER, R A (1969) Minnesota Nosema survey. American Bee Journal 109(12): 460-461.

FURGALA, B, MAUNDER, M J (1961) A simple method of feeding Nosema apis inoculum to individual honey bees. Bee World 42(10): 249-252. FURGALA, B; MUSSEN, E C (1978) Protozoa. In Morse, $R$ A; Nowogrodzki, $R$ (Eds) Honey bee pests, predators, and diseases. Cornell University Press; Ithaca, USA. pp. 48-63.
GENERSCH, E; GISDER, S; HEDTKE, K; HUNTER, W B; MÖCKEL, N; MÜLLER, U (2013) Standard methods for cell cultures in Apis mellifera research. In V Dietemann; J D Ellis; P Neumann (Eds) The COLOSS BEEBOOK, Volume I: standard methods for Apis mellifera research. Journal of Apicultural Research 52(1): http://dx.doi.org/10.3896/IBRA.1.52.1.02

GISDER, S; HEDTKE, K; MÖCKEL, N; FRIELITZ, M C; LINDE, A; GENERSCH, E (2010a) Five-year cohort study of Nosema spp. in Germany: climate shape virulence and assertiveness of Nosema ceranae? Applied and Environmental Microbiology 76(9): 30323038. http://dx.doi.org/10.1128/AEM.03097-09

GISDER, S; MÖCKEL, N; LINDE, A; GENERSCH, E (2010b) A cell culture model for Nosema ceranae and Nosema apis allows new insights into the life cycle of these important honey beepathogenic microsporidia. Environmental Microbiology. 13(2): 404 -413. http://dx.doi.org/10.1111/j.1462-2920.2010.02346.x

GROSS, K P; RUTTNER, F (1970) Entwickelt Nosema apis Zander eine Resistenz gegenüber dem Antibiotikum Fumidil B? Apidologie 1 (4): 401-422. http://dx.doi.org/10.1051/apido:19700403 GRÜNEWALD, B; WERSING, A (2008) An ionotropic GABA receptor in cultured mushroom body Kenyon cells of the honey bee and its modulation by intracellular calcium. Journal of Comparative Physiology A Neuroethology Sensory Neural and Behavioural Physiology 194(4): 329-340.

http://dx.doi.org/10.1007/s00359-007-0308-9

GUZMAN-NOVOA, E; CORREA-BENITEZ, A; ECCLES, L; CALVETE, Y; MCGOWAN, J; KELLY, P G (2010) Varroa destructor is the main culprit for the death and reduced populations of overwintered honey bee (Apis mellifera) colonies in Ontario, Canada. Apidologie 41(4): 443-450. http://dx.doi.org/10.1051/apido/2009076 HAMIDUZZAMAN, M M; GUZMAN-NOVOA, E; GOODWIN, P H (2010) A multiplex PCR assay to diagnose and quantify Nosema infections in honey bees (Apis mellifera). Journal of Invertebrate Pathology 105(2): 151-155. http://dx.doi.org/10.1016/j.jip.2010.06.001

HASSANEIN, M H (1953) The influence of infection with Nosema apis on the activities and longevity of worker honey bees. Annals of Applied Biology 40(2): 418-423. http://dx.doi.org/10.1111/j.1744-7348.1953.tb01093.x HIGES, M; GARCÍA-PALENCIA, P; BOTÍAS, C; MEANA, A; MARTÍNHERNÁNDEZ, R (2010) The differential development of microsporidia infecting worker honey bee (Apis mellifera) at increasing incubation temperature. Environmental and Microbiology Reports 2(6): 745-748. http://dx.doi.org/10.1111/j.1758-2229.2010.00170x HIGES, M; GARCÍA-PALENCIA, P; MARTÍN-HERNÁNDEZ, R; MEANA, A (2007) Experimental infection of Apis mellifera honey bees with Nosema ceranae (Microsporidia). Journal of Invertebrate Pathology 94(3): 211-217. http://dx.doi.org/10.1016/j.jip.2006.11.001 
HIGES, M; MARTIN-HERNANDEZ, R; BOTIAS, C; BAILON, E G; GONZALES-PORTO, A V; BARRIOS, L; DEL NOZAL, M J; BERNAL, J L; JIMENEZ, J J; PALENCIA, P G; MEANA, A (2008a) How natural infection by Nosema ceranae causes honey bee colony collapse. Environmental Microbiology 10(10): 2659-2669. http://dx.doi.org/10.1111/j.1462-2920.2008.01687.x HIGES, M; MARTÍN-HERNÁNDEZ, R; GARRIDO-BAILÓN, E; GARCÍAPALENCIA, P; MEANA, A (2008b) Detection of infective Nosema ceranae (Microsporidia) spores in corbicular pollen of forager honey bees. Journal of Invertebrate Pathology 97(1): 76-78. http://dx.doi.org/10.1016/j.jip.2007.06.002

HIGES, M; MARTIN-HERNANDEZ, R; MEANA, A (2006) Nosema ceranae, a new microsporidian parasite in honey bees in Europe. Journal of Invertebrate Pathology 92(2): 93-95.

http://dx.doi.org/10.1016/j.jip.2006.02.005

HIGES, M; NOZAL, M J; ALVARO, A; BARRIOS, L; MEANA, A; MARTINHERNANDEZ, R; BERNAL, J L; BERNAL, J (2011) The stability and effectiveness of fumagillin in controlling Nosema ceranae (Microsporidia) infection in honey bees (Apis mellifera) under laboratory and field conditions. Apidologie 42(4): 364-377. http://dx.doi.org/10.1007/s13592-011-0003-2

HIGES, M; PILAR, G P; MARTIN-HERNANDEZ, R; ARANZAZU, M (2007) Experimental infection of Apis mellifera honey bees with Nosema ceranae (Microsporidia). Journal of Invertebrate Pathology 94(3): 211-217. http://dx.doi.org/10.1016/j.jip.2006.11.001

HUMAN, H; BRODSCHNEIDER, R; DIETEMANN, V; DIVELY, G; ELLIS, J; FORSGREN, E; FRIES, I; HATJINA, F; HU, F-L; JAFFÉ, R; KÖHLER, A; PIRK, C W W; ROSE, R; STRAUSS, U; TANNER, G; VAN DER STEEN, J J M; VEJSN/ES, F; WILLIAMS, G R; ZHENG, H-Q (2013) Miscellaneous standard methods for Apis mellifera research. In $V$ Dietemann; J D Ellis; P Neumann (Eds) The COLOSS BEEBOOK, Volume I: standard methods for Apis mellifera research. Journal of Apicultural Research 52(4):

http://dx.doi.org/10.3896/IBRA.1.52.4.10

HUNTER, W B (2010) Medium for development of bee cell cultures (Apis mellifera: Hymenoptera: Apidae). In Vitro Cell Developmental Biology Animal 46(2): 83-86.

http://dx.doi.org/10.1007/s11626-009-9246-x

INVERNIZZI, C; ABUD, C; TOMASCO, I H; HARRIET, J; RAMALLO, G; CAMPA, J; KATZ, H; GARDIOL, G; MENDOZA, Y (2009) Presence of Nosema ceranae in honey bees (Apis mellifera) in Uruguay. Journal of Invertebrate Pathology 101(2): 150-153.

http://dx.doi.org/10.1016/j.jip.2009.03.006

JARONSKI, S T (1984) Microsporidia in cell culture. Advances in Cell Culture 3: 183-229.
KATZNELSON, H; ROBB, J A (1962) The use of gamma radiation from cobalt- 60 in the control of diseases of the honey bee and the sterilization of honey. Canadian Journal of Microbiology 8(2): 175-179.

KELLNER, N; JACOBS, F J (1978) In hoeveel tijd bereiken de sporen van Nosema apis Zander de ventriculus van de honingbij (Apis mellifera L.)? Vlaams Diergeneeskundig Tijdschrift 47(3): 252-259.

KLEE, J; BESANA, A M; GENERSCH, E; GISDER, S; NANETTI, A; TAM, D Q; CHINH, T X; PUERTA, F; RUZ, J M; KRYGER, P; MESSAGE, D; HATJINA, F; KORPELA, S; FRIES, I; PAXTON, R J (2007) Widespread dispersal of the microsporidian Nosema ceranae, an emergent pathogen of the western honey bee, Apis mellifera. Journal of Invertebrate Pathology 96(1): 1-10. http://dx.doi.org/10.1016/j.jip.2007.02.014

KLEE, J; TAY, W T; PAXTON, R J (2006) Specific and sensitive detection of Nosema bombi (Microsporidia : Nosematidae) in bumble bees (Bombus spp.; Hymenoptera : Apidae) by PCR of partial rRNA gene sequences. Journal of Invertebrate Pathology 91(2): 98-104. http://dx.doi.org/10.1016/j.jip.005.10.012

KRAUS, B; VELTHUIS, H H W (1997) High humidity in the honey bee (Apis mellifera L.) brood nests limits reproduction of the parasitic mite Varroa jacobsoni Oud. Naturwissenschaften 84(5): 217-218. http://dx.doi.org/10.1007/s001140050382

KREISSL, S; BICKER, G (1992) Dissociated neurons of the pupal honey bee brain in cell culture. Journal of Neurocytology 21(8): 545-556. http://dx.doi.org/10.1007/BF01187116

L'ARRIVEE, J C M (1963) Comparison of composite versus individual bee sampling for Nosema apis Zander. Journal of Insect Pathology 5(4): 349-355.

LI, J; CHEN, W; WU, J; PENG, W; AN, J; SCHMID-HEMPEL, P; SCHMID-HEMPEL, R (2012) Diversity of Nosema associated with bumble bees (Bombus spp.) from China. International Journal of Parasitology 42(1):49-61. http://dx.doi.org/10.1016/j.jpara.2011.10.005

LINDER, A (1947) Über das Auswerten zahlenmässiger Angaben in der Bienenkunde. Beihefte zur Schweizerischen Bienen-Zeitung 2: 77-138.

LYNN, D E (2007) Available lepidopteran insect cell lines. In Murhammer, DW (Ed.) Methods in molecular biology 388. Humana Press Inc.; Totowa, NJ, USA. pp. 117-138.

LOSKOTOVA, J; PEROUTKA, M; VESLEY, V (1980) Nosema disease of honey bee queens (Apis mellifica L.). Apidologie 11(2): 153-161. http://dx.doi.org/10.1051/apido:19800205

MAISTRELLO, L; LODESANI, M; COSTA, C; LEONARDI, F; MARANI, G; CALDON, M; MUTINELLI, F; GRANATO, A (2008) Screening of natural compounds for the control of nosema disease in honey bees. Apidologie 39(4): 436-445. http://dx.doi.org/10.1051/apido:2008022 
MALONE, L A; GATEHOUSE, H S; TREGIDGA, E L (2001) Effects of time, temperature, and honey on Nosema apis (Microsporidia: Nodematidae) a parasite of the honey bee, Apis mellifera (Hymenoptera: Apidae). Journal of Invertebrate Pathology 77(4): 258-268. http://dx.doi.org/10.1006/jipa.2001.5028

MALONE, L A; STEVANOVIC, D (1999) Comparison of the responses of two races of honey bees to infection with Nosema apis Zander. Apidologie 30(5): 375-382.

http://dx.doi.org/10.1051/apido:19990503

MARTÍN-HERNÁNDEZ, R; BOTIAS, C; BARRIOS, L; MARTINEZSALVADOR, A; MEANA, A; MAYACK, C; HIGES, M (2011) Comparison of the energetic stress associated with experimental Nosema ceranae and Nosema apis infection of honey bees (Apis mellifera). Parasitology Research 109(3): 605-612.

http://dx.doi.org/10.1007/s00436-011-2292-9

MARTÍN-HERNÁNDEZ, R; MEANA, A; GARCÍA-PALENCIA, P; MARÍN, P; BOTÍAS, C; GARRIDO-BAILÓN, E; BARRIOS, L; HIGES, M (2009). Effect of temperature on the biotic potential of honey bee microsporidia. Applied and Environmental Microbiology 75(8): 2554-2557. http://dx.doi.org/10.1128/AEM.02908-08 MARTÍN-HERNÁNDEZ, R; MEANA, A; PRIETO, L; MARTINEZSALVADOR, A; GARRIDO-BAILÓN, E; HIGES, M (2007) Outcome of colonization of Apis mellifera by Nosema ceranae. Applied and Environmental Microbiology 73(20): 6331-6338.

http://dx.doi.org/10.1128/AEM.00270-07

MAYACK, C; NAUG, D (2009) Energetic stress in the honey bee Apis mellifera from Nosema ceranae infection. Journal of Invertebrate Pathology 100(3): 185-188. http://dx.doi.org/10.1016/j.jip.2008.12.001 MCMULLAN, J B; BROWN, M J F (2005) Brood pupation temperature affects the susceptibility of honey bees (Apis mellifera) to infestation by tracheal mites (Acarapis woodl). Apidologie 36(1): 97-105. http://dx.doi.org/10.1051/apido:2004073

MEANA, A; MARTÍN-HERNÁNDEZ, R; HIGES, M (2010) The reliability of spore counts to diagnose Nosema ceranae infections in honey bees. Journal of Apicultural Research 49(2): 212-214.

MEIXNER, M D; PINTO, M A; BOUGA, M; KRYGER, P; IVANOVA, E; FUCHS, $S$ (2013) Standard methods for characterising subspecies and ecotypes of Apis mellifera. In V Dietemann; J D Ellis; $P$ Neumann (Eds) The COLOSS BEEBOOK, Volume I: standard methods for Apis mellifera research. Journal of Apicultural Research 52(4): http://dx.doi.org/10.3896/IBRA.1.52.4.05

MICHAILOFF, A S (1928) Statistische Untersuchungen über Nosema an der Tulaer Versuchsstation für Bienenzucht. Archive für Bienenkunde 9: 89-114.

OFFICE INTERNATIONAL DES EPIZOOTIES (OIE) (2008) Nosemosis of honey bees. [WWW document].URL http://www.oie.int/eng/ normes/mmanual/2008/pdf/2.02.04_NOSEMOSIS.pdf
PAXTON, R J; FRIES, I; PIENIAZEK, N J; TENGÖ, J (1997) High incidence of infection of an undescribed microsporidium (Microspora) in the communal bee Andrena scotica (Hymenoptera, Andrenidae) in Sweden. Apidologie 28: 129-141. http://dx.doi.org/10.1051/apido:19970304

PAXTON, R J; KLEE, J; KORPELA, S; FRIES, I (2007) Nosema ceranae has infected Apis mellifera in Europe since at least 1998 and may be more virulent than Nosema apis. Apidologie 38(6): 558-565. http://dx.doi.org/10.1051/apido:2007037

PERNAL, S F; CURRIE, R W (2000) Pollen quality of fresh and 1-yearold single pollen diets for worker honey bees (Apis mellifera L.). Apidologie 31(3): 387-409. http://dx.doi.org/10.1051/apido:2000130 PETTIS, J S; VANENGELSDORP, D; JOHNSON, J; DIVELY, G (2012) Pesticide exposure in honey bees results in increased levels of the gut pathogen Nosema. Naturwissenschaften 99(2): 153-158. http://dx.doi.org/10.1007/s00114-011-0881-1

PORRINI, M P; AUDISIO, M C; SABATE, D C; IBARGUREN, C; MEDICI S K; SARLO, E G; GARRIDO, P M; EGUARAS, M J (2010) Effect of bacterial metabolites on microsporidian Nosema ceranae and on its host Apis mellifera. Parasitology Research 107(2): 381-388. http://dx.doi.org/10.1007/s00436-010-1875-1

PORRINI, M P; SARLO, E G; MEDICI, S K; GARRIDO, P M; PORRINI, D P; DAMIANI, N; EGUARAS, M J (2011) Nosema ceranae development in Apis mellifera: influence of diet and infective inoculum. Journal of Apicultural Research 50(1): 35-41. http://dx.doi.org/10.3896/IBRA.1.50.1.04

RIBBANDS, C R (1950) Changes in the behaviour of honey bees following their recovery from anaesthesia. Journal of Experimental Biology 27(3-4): 302-310.

RUEPPELL, O; HAYWORTH, M K; ROSS, N P (2010) Altruistic selfremoval of health-compromised honey bee workers from their hive. Journal of Evolutionary Biology 23(7): 1538-1546. http://dx.doi.org/10.1111/j.1420-9101.2010.02022.x

RUTRECHT, S T; BROWN, M J F (2008) Within colony dynamics of Nosema bombi infections: disease establishment, epidemiology and potential vertical transmission. Apidologie 39(5): 504-514. http://dx.doi.org/10.1051/apido:2008031

RUTRECHT, S T; KLEE, J; BROWN, M J F (2007) Horizontal transmission success of Nosema bombi to its adult bumble bee hosts: effects of dosage, spore source and host age. Parasitology 134: 1719-1726.

SAGASTUME, S; DEL ÁGUILA, C; MARTÍN-HERNÁNDEZ, R; HIGES, M; HENRIQUES-GIL, N (2011) Polymorphism and recombination for rDNA in the putatively asexual microsporidian Nosema ceranae, a pathogen of honey bees. Environmental Microbiology 13(1): 84-95. http://dx.doi.org/10.1111/j.1462-2920.2010.02311.x SCHMIDT, J O; THOENES, S C; LEVIN, M D (1987) Survival of honey bees, Apis mellifera (Hymenoptera: Apidae), fed various pollen sources. Annals of the Entomological Society of America 80(2): 176-183. 
SMAGGHE, G; GOODMAN, C L; STANLEY, D (2009) Insect cell culture and applications to research and pest management. In Vitro Cell Developmental Biology Animal 45(3-4): 93-105.

http://dx.doi.org/10.1007/s11626-009-9181-x

SMART, M D; SHEPPARD, W S (2011) Nosema ceranae in age cohorts of the western honey bee (Apis mellifera). Journal of Invertebrate Pathology 109(1): 148-151.

http://dx.doi.org/10.1016/j.jip.2011.09.009.

TAY, W T; O'MAHONEY, E M; PAXTON, R J (2005) Complete rRNA gene sequences reveal that the microsporidium Nosema bombi infects diverse bumble bee (Bombus spp.) hosts and contains multiple polymorphic sites. Journal of Eukaryotic Microbiology 52 (6): 505-513. http://dx.doi.org/10.1111/j.550-7408.2005.00057.x

TANNER, G; WILLIAMS, G R; MEHMANN, M; NEUMANN, P (2012) Comparison of mass versus individual inoculation of worker honey bees with Nosema ceranae. In Proceedings of the $8^{\text {th }}$ COLOSS Conference / MC meeting FA0803. Halle-Saale, Germany, 1-3 September 2012. p 59.

TENTCHEVA, D; GAUTHIER, L; ZAPPULLA, N; DAINAT, B; COUSSERANS, F; COLIN, M E; BERGOIN, M (2004) Prevalence and seasonal variations of six bee viruses in Apis mellifera L. and Varroa destructor mite populations in France. Applied and Environmental Microbiology 70(12): 7185-7191. http://dx.doi.org/0.1128/AEM.70.12.7185-7191.2004

TRAVER, B E; FELL, R D (2011) Prevalence and infection intensity of Nosema in honey bee (Apis mellifera L.) colonies in Virginia. Journal of Invertebrate Pathology 107(1): 43-49. http://dx.doi.org/10.1016/j.jip.2011.02.003

TRAVER, B E; FELL, R D (2012) Low natural levels of Nosema ceranae in Apis mellifera queens. Journal of Invertebrate Pathology 110(3): 408-410. http://dx.doi.org/10.1016/j.jip.2012.04.001

TRAVER, B E; WILLIAMS, M R; FELL, R D (2012) Comparison of within hive sampling and seasonal activity of Nosema ceranae in honey bee colonies. Journal of Invertebrate Pathology 109(2): 187-193. http://dx.doi.org/10.1016/j.jip.2011.11.001

TROEMEL, E R (2011) New models for microsporidiosis: infections in zebrafish, C. elegans and honey bee. PLoS Pathology 7(2): e1001243. http://dx.doi.org/10.1371/journal.ppat.1001243

VAN OERS, M M; LYNN, D E (2010) Insect cell culture. eLS. Wiley online Library. http://dx.doi.org/10.1002/9780470015902.a0002574.pub2

VAVRA, J; LARSSON, R (1999) Structure of the microsporidia. In Wittner, M; Weiss [initials?] (Eds) The microsporidia and microsporidiosis. ASM Press; Washington D C; USA. pp. 7-84.

VERBEKE, M; JACOBS, F J; DE RYCKE, P H (1984) Passage of various particles through the ventriculus in the honey bee (Apis mellifera L.). American Bee Journal 123(6): 468-470.
WANG, D-I, MOELLER, F E (1970) The division of labor and queen attendance behaviour of nosema-infected worker honey bees. Journal of Economic Entomology 63(5): 1539-1541.

WEBSTER, T C (1994) Fumagillin effects on Nosema apis and honey bees (Hymenoptera: Apidae). Journal of Economic Entomology 87 (3): 601-604.

WEBSTER, T C (2008) Nosema apis infection in honey bee (Apis mellifera) queens. Journal of Apicultural Research 47(1): 53-57.

WEBSTER, T C; POMPER, K W; HUNT, G; THACKER, E M; JONES, S C (2004) Nosema apis infection in worker and queen Apis mellifera. Apidologie 35(1): 49-54. http://dx.doi.org/10.1051/apido:2003063 WHITE, G F (1919) Nosema disease. US Department of Agriculture Bulletin 780 .

WILLIAMS, G R; SHAFER SHAFER, A B A; ROGERS, R E L; SHUTLER, D; STEWART, D T (2008) First detection of Nosema ceranae, a microsporidian parasite of European honey bees (Apis mellifera), in Canada and central USA. Journal of Invertebrate Pathology 97 (2): 189-192. http://dx.doi.org/10.1016/j.jip.2007.08.005

WILLIAMS, G R; ALAUX, C; COSTA, C; CSÁKI, T; DOUBLET, V; EISENHARDT, D; FRIES, I; KUHN, R; MCMAHON, D P; MEDRZYCKI, P; MURRAY, T E; NATSOPOULOU, M E; NEUMANN, P; OLIVER, R; PAXTON, R J; PERNAL, S F; SHUTLER, D; TANNER, G; VAN DER STEEN, J J M; BRODSCHNEIDER, R (2013) Standard methods for maintaining adult Apis mellifera in cages under in vitro laboratory conditions. In V Dietemann; J D Ellis; P Neumann (Eds) The COLOSS BEEBOOK, Volume I: standard methods for Apis mellifera research. Journal of Apicultural Research 52(1): http://dx.doi.org/10.3896/IBRA.1.52.1.04

WILLIAMS, G R; ROGERS, R E L; KALKSTEIN, A L; TAYLOR, B A; SHUTLER, D; OSTIGUY, N (2009) Deformed wing virus in western honey bees (Apis mellifera) from Atlantic Canada and the first description of an overtly-infected emerging queen. Journal of Invertebrate Pathology 101(1): 77-79. http://dx.doi.org/10.1016/j.jip.2009.01.004

WILLIAMS, G R; SHUTLER, D; ROGERS, R E L (2010) Effects at Nearctic north-temperate latitudes of indoor versus outdoor overwintering on the microsporidium Nosema ceranae and western honey bees (Apis mellifera). Journal of Invertebrate Pathology 104(1): 4-7. http://dx.doi.org/10.1016/j.jip.2010.01.009

WILLIAMS, G R; SHUTLER, D; LITTLE, C M; BURGHER-MACLELLAN, K L; ROGERS, R E L (2011) The microsporidian Nosema ceranae, the antibiotic Fumagilin- $\mathrm{B}^{\circledR}$, and western honey bee (Apis mellifera) colony strength. Apidologie 41(1): 15-22. http://dx.doi.org/10.1051/apido/20100230.

WILSON, W T; NUNAMAKER, R A (1983) The incidence of Nosema apis in honey bees in Mexico. Bee World 64(3): 132-136. 
WOYCIECHOWSKI, M; MORON, D (2009) Life expectancy and onset of foraging in the honey bee ( Apis mellifera). Insectes Sociaux 56 (2): 193-201. http://dx.doi.org/10.1007/s00040-009-0012-6 YUE, C; SCHRÖDER, M; GISDER, S; GENERSCH, E (2007) Verticaltransmission routes for deformed wing virus of honey bees (Apis mellifera). Journal of General Virology 88: 2329-2336.

http://dx.doi.org/10.1099/vir.0.83101-0
ZANDER, E (1909) Tierische Parasiten als Krankenheitserreger bei der Biene. Münchener Bienenzeitung 31, 196-204.

ZANDER, E; BÖTTCHER, F K (1984) Krankheiten der Biene, 7:e. edition. Verlag Eugen Ulmer, Stuttgart, Germany. 408 pp. 